\title{
Context-dependent roles for lymphotoxin- $\beta$ receptor signaling in cancer development
}

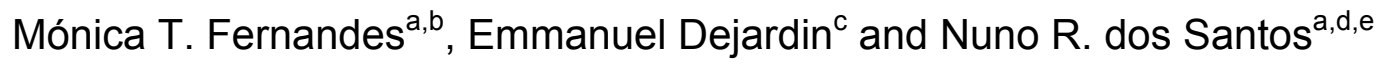 \\ ${ }^{a}$ Centre for Biomedical Research (CBMR), University of Algarve, 8005-139 Faro, Portugal; \\ ${ }^{b}$ PhD Program in Biomedical Sciences, Department of Biomedical Sciences and Medicine, University \\ of Algarve, 8005-139 Faro, Portugal; \\ ${ }^{c}$ Laboratory of Molecular Immunology and Signal Transduction, GIGA-Research, Molecular Biology of \\ Diseases, University of Liège, 4000 Liège, Belgium; \\ ${ }^{d}$ Instituto de Investigação e Inovação em Saúde (I3S), Universidade do Porto, 4200 Porto, Portugal;

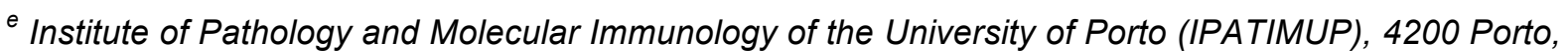 \\ Portugal.
}

Corresponding author at: Centre for Biomedical Research (CBMR), University of Algarve, Campus de Gambelas, 8005-139 Faro, Portugal; Tel.: +351 289800900 (+7136). E-mail address: nrsantos@ualg.pt (N.R.dos Santos).

\begin{abstract}
The $L T \alpha_{1} \beta_{2}$ and LIGHT TNF superfamily cytokines exert pleiotropic physiological functions through activation of their cognate lymphotoxin- $\beta$ receptor (LT $\beta R)$. Interestingly, since the discovery of these proteins accumulating evidence has pinpointed a role for LT $\beta R$ signaling in carcinogenesis. Early studies have shown a potential anti-tumoral role in a subset of solid cancers either by triggering apoptosis in malignant cells or by eliciting an anti-tumor immune response. However, more recent studies provided robust evidence that LT $\beta R$ signaling is also involved in diverse cell-intrinsic and microenvironment-dependent pro-oncogenic mechanisms, affecting several solid and hematological malignancies. Consequently, the usefulness of LT $\beta R$ signaling axis blockade has been investigated as a potential therapeutic approach for cancer. Considering the seemingly opposite roles of LT $\beta R$ signaling in diverse cancer types and their key implications for therapy, we here extensively review the different mechanisms by which LT $\beta R$ activation affects carcinogenesis, focusing on the diverse contexts and different models assessed.
\end{abstract}

Keywords: Lymphotoxin- $\beta$ receptor; cell signaling; lymphotoxin; LIGHT; oncogenesis; tumor microenvironment. 


\section{Introduction}

Lymphotoxin- $\beta$ receptor $(L T \beta R)$ is a member of the tumor necrosis factor receptor superfamily (TNFRSF) identified as a key mediator controlling the development, organization and homeostasis of lymphoid tissues and organs [1-3]. Moreover, it was reported to play a role in the adaptive immune response against pathogens [1], thymic medullary epithelial cell differentiation and central tolerance induction [4]. Currently it is known that LT $\beta R$ is involved in many other biological processes such as liver regeneration [5], lipid homeostasis [6], high endothelial venule (HEV) differentiation and function [7], and protection against atherosclerosis [8]. Considering the immune system functions of LTRR signaling it is not unexpected that its deregulation leads to autoimmune and inflammatory diseases, including rheumatoid arthritis [9,10], Sjögren's syndrome [11], autoimmune pancreatitis [12], hepatitis [13], and colitis [14]. Importantly, LT $\beta R$ signaling has also been reported to be involved in cancer [15,16], albeit with contrasting, context-dependent effects. These effects and the current understanding of the LT $\beta R$ signaling role in cancer development are the main focus of this review.

\section{LT $\beta R$ and its ligands: lymphotoxin and LIGHT}

The human LTBR gene (LTBR or TNFRSF3) is located on chromosome (Chr) 12 (Figure $1 \mathrm{~A}$ ), in proximity to genes encoding other TNFRSF members, namely TNFR1 (TNFRSF1A) and CD27 (TNFRSF7) [17,18]. The LTBR full-length transcript encodes a 435-amino acid type I glycosylated protein consisting of three main domains: extracellular (ECD), transmembrane (TMD), and intracellular domain (ICD), also known as cytoplasmic domain (CD) (Figure 1B). Like other TNFRSF receptors, LT $\beta R$ displays four cysteine-rich domains (CRD) in the ECD, which confer receptor specificity and affinity for the cognate ligands [17], but it does not contain a death domain in the cytoplasmic tail. It rather harbors here a proline-rich membrane proximal region [17] and two binding sites for members of the TNF receptor-associated factor (TRAF) family of zinc RING finger proteins [19]. Indeed, TRAF2 [20], TRAF3 [21], TRAF4 [22] and TRAF5 [23] have been reported to associate with LT $\beta$. Moreover, within the TRAF-binding domain, distinct regions mediate self-interaction, receptor intracellular trafficking, and the activation of downstream signaling pathways like those activating NF-KB and those leading to cell death [24].

LT $\beta R$ has been shown to be constitutively expressed by a wide variety of cells in lymphoid and visceral tissues such as epithelial and endothelial cells, follicular dendritic cells (FDCs), fibroblasts, and myeloid lineage cells (e.g., monocytes, dendritic cells (DCs), and 
mast cells), but not on lymphocytes $[14,18,25,26]$. Since the only two known ligands for LT $\beta R$, lymphotoxin (LT) $\alpha_{1} \beta_{2}$ heterotrimers and LIGHT/TNFSF14 homotrimers, are physiologically expressed in lymphocytes [27-29], this pattern of expression suggests that most if not all signals mediating LT $\beta R$ activation are paracrine or juxtacrine in nature.

The genes encoding LTa, the TNF superfamily (TNFSF) member 1 (TNFSF1 or LTA) and LT $\beta$, the TNFSF member 3 (TNFSF3 or $\angle T B$ ), reside in a tightly linked locus within the MHC class III region in human Chr 6, flanking the gene encoding TNFa (TNFSF2 or TNFA) (Figure 1A) [30-33]. The human full-length LTa mRNA encodes a 205-amino acid type II glycosylated protein, also known as TNF $\beta$ [33], while the full-length LT $\beta$ mRNA encodes a 244-amino acid type II glycosylated protein [30]. In contrast to the LT $\beta$ protein, which comprises a short N-terminal CD, a TMD and a C-terminal ECD [30], LTa lacks a TMD (Figure 1B). Therefore, when expressed in the absence of LT $\beta$, LTa forms soluble $\mathrm{LTa}_{3}$ homotrimers stabilized primarily by interactions between hydrophobic and aromatic side chains $[18,34,35]$. When LTa is expressed together with LT $\beta$, these proteins oligomerize generating cell-surface $L \mathrm{La}_{1} \beta_{2}$ heterotrimers $[18,36,37]$. $L \mathrm{La}_{2} \beta_{1}$ heterotrimers can also form, but these are a minor form detectable only in vitro and representing less than $10 \%$ of total LTa $\beta$ heterotrimers [37]. The LTa subunit contributes primarily to the conformation of the heterotrimer [35], while the LT $\beta$ subunit provides the membrane anchor for $L T \alpha_{1} \beta_{2}$ and confers specificity for LT $\beta R$ binding [17]. LTB but not LTA expression in lymphocytes is constitutive but both are induced by cell stimulation [30]. The reported basal levels of $L T B$ mRNA in lymphoid cells may be important to interact with and transport LTa to the cell surface as an $L T \alpha_{1} \beta_{2}$ heterotrimer (instead of $L T \alpha_{2} \beta_{1}$ or even soluble $L T \alpha_{3}$ ). Being inducible, LTa production is probably the rate-limiting step in this process $[30,38,39]$.

The LTa- and LT $\beta$-encoding genes display a restricted and similar pattern of expression, being mainly expressed in hematopoietic cells including activated $\mathrm{T}$ and $\mathrm{B}$ cells, natural killer (NK) cells [27,29], DCs [40] and lymphoid-tissue inducer (LTi) cells [41]. Cellsurface $\mathrm{LTa}_{1} \beta_{2}$ heterotrimers are upregulated through lymphocyte activation, but also by cytokine and chemokine induction. For example, $L \mathrm{LT}_{1} \beta_{2}$ is induced by IL-2 on human peripheral blood T cells [29], and IL-4, IL-7, CCL19 and CCL21 in murine splenic T cells [42]. Induction of $L T \alpha_{1} \beta_{2}$ expression by viral proteins in infected hepatocytes $[13,43]$ and cervical epithelium [44] was also reported.

The other known LTRR ligand is encoded by the human TNFSF member 14 (TNFSF14) or LIGHT gene and is located within an MHC paralog region on Chr 19, in close proximity to other TNFSF genes such as those encoding CD27L/CD70 (TNFSF7) and CD137L/4-1BB (TNFSF9) (Figure 1A) [45,46]. The LIGHT full-length transcript is translated into a 240-amino acid glycosylated type II transmembrane protein (Figure 1B) [45]. LIGHT monomers form homotrimers at the cell surface of activated lymphocytes [28], which can be 
shed upon proteolytic cleavage [45]. Similarly to lymphotoxin genes, the LIGHT-encoding gene displays a restricted expression pattern being mainly expressed on activated peripheral blood $\mathrm{T}$ lymphocytes [28], monocytes, granulocytes and immature DCs $[40,47,48]$, and also on mucosal tissue-derived CD4 ${ }^{+} \mathrm{T}$ and NK cells [49]. LIGHT was shown to be expressed also in thymic stromal cells such as DCs, fibroblasts, and endothelial and epithelial cells [26].

Some TNFSF members can bind the same receptor, as is the case for $L T \alpha / L T \beta-$ containing ligands and LIGHT. LTa ${ }_{3}$ binds TNFR1, TNFR2 [50,51], and herpes virus entry mediator (HVEM) [28,50], a receptor expressed by $T$ and $B$ cells, NK cells, DCs and monocytes [52]. Since the LT $\beta R$ discovery, no other receptor for $L T \alpha_{1} \beta_{2}$ has been found [37]. In contrast, $\operatorname{LTa}_{2} \beta_{1}$ heterotrimers may bind not only $\operatorname{LT} \beta R$, albeit with low affinity $[17,35,37]$, but also TNFR1 and TNFR2 [17,37]. LIGHT forms only homotrimers, which can bind and activate LT $\beta R$ and HVEM [28], and the soluble decoy receptor 3 (DcR3), which acts as a negative regulator [53]. Although several of these interactions were reported in vitro (e.g. $\mathrm{LTa}_{2} \beta_{1}$ binding to TNFR1/2), their physiological relevance in vivo remains questionable.

Even though both $L T \alpha_{1} \beta_{2}$ heterotrimers and LIGHT homotrimers are often found at the cell membrane, in certain contexts they can be shed from the cell surface. For instance, $L \mathrm{Ta}_{1} \beta_{2}$ can be shed from human activated $\mathrm{T}$ cells, upon proteolysis mediated by matrix metalloproteinase (MMP)-8 and ADAM17/TNFa converting enzyme (TACE), to induce the expression of pro-inflammatory genes on synovial fibroblasts from rheumatoid arthritis patients [10]. LIGHT can also be actively shed from the cell surface of CD4 ${ }^{+} \mathrm{T}$ lymphocytes by MMPs in rheumatoid arthritis [54] but also in the context of immune cell regulation [55]. Although the soluble form of LIGHT binds and activates HVEM, the membrane-bound homotrimer shows enhanced activation of this receptor [45,56,57]. Interestingly, the membrane-bound form of LIGHT expressed in T lymphocytes has been shown to act as a Tcell receptor (TCR) costimulatory signal when bound either to an agonistic antibody or to its receptor DcR3, a phenomenon denominated reverse signaling $[58,59]$. Nevertheless, the biological significance of these different LIGHT forms is still not fully understood especially regarding LT $\beta R$ activation. In certain contexts LIGHT shedding may induce distal functional effects on LT $\beta R$ activation or may serve as a mechanism of self-inactivation [45].

\section{LT $\beta R$ activation, NF-KB signal transduction and target gene regulation}

The TNFRSF members are typically activated by ligand-induced trimerization or even higher order oligomerization through the interaction of receptor CRD domains with each monomermonomer interface groove [60]. As no exception to this notion, the central initiating event for 
LT $\beta R$ signaling is receptor aggregation. However, unlike other TNF receptors, each LT $\beta R$ subunit can bind only two sites in the $L T a_{1} \beta_{2}$ heterotrimer, the LTa-LT $\beta$ (higher affinity) and LT $\beta$-LT $\beta$ ' (lower affinity) interfaces for productive receptor activation [61]. Similarly, LIGHT has been shown to present only two high-affinity binding sites for LTRR [62]. Thus, the binding of $L T \alpha_{1} \beta_{2}$ or LIGHT to LT $\beta R$ brings two receptor molecules in close proximity (Figure 1C) $[61,62]$ and the $L T \beta R$ self-interaction region in the cytoplasmic domain promotes receptor aggregation and consequent conformational changes [24]. These events lead to the sequential recruitment of cytosolic adaptor proteins to the cytoplasmic region of LT $\beta R$, mainly TRAF proteins. These proteins may activate or repress signaling initiation leading to gene transcription through different signaling pathways such as the classical and the alternative NF-KB pathways, the c-Jun N-terminal kinase (JNK) MAP kinase pathway, and other signaling pathways leading to cell death [63] (Figure 2). LT $\beta R$-dependent downstream signaling can also be initiated independently of ligand binding either artificially by anti-LTßR agonistic antibodies that induce receptor aggregation [21,64], or pathologically by receptor overexpression leading to self-association $[19,65,66]$.

Although $L T \beta R$ activation has been reported to induce gene expression through ASK-MKK-JNK-dependent AP-1 activation [67,68] and LT $\beta R$ interacts with the AP2 adaptor/clathrin complex to mediate unknown NF-kB-independent functions [19], cell death induction and NF-KB activation are the most studied events downstream LT $\beta$. Despite lacking a cell death domain in its cytosolic domain, LT $\beta R$ has been shown to induce death of cancer cell lines (e.g., HT-29, WiDr, Hep3BT2, and MCF-7) and to arrest tumor growth in cell line-derived xenograft models $[69,70]$. LT $\beta R$ activation was shown to lead to cell death in the presence of IFN- $\gamma$ [69] by either caspase-dependent (apoptosis) and/or caspaseindependent (necroptosis/necrosis) mechanisms [20,71-74]. In addition, LT $\beta R$ activation in combination with TNFR1 was proven essential to sensitize cortical thymic epithelial cells (cTECs) to TNFR1-mediated cell death $[75,76]$. The mechanism was shown to rely on NIK activation and on assembly of the RIP1/FADD/caspase8 death complex (Figure 2), but not on processing of $\mathrm{p} 100$ to $\mathrm{p52}$, an essential step in the NF-KB alternative pathway [77]. Despite these findings, further research is warranted to fully understand the mechanisms of cell death induced by LT $\beta R$, which may depend on cell type, nature of the LT $\beta R$-activating stimulus and co-activation of other receptors.

Unlike the prototypical TNF receptors, which activate the classical but not the alternative NF-KB pathway (i.e., TNFR1), but like other TNFRSF members (e.g., BAFFR, CD40, CD27, Tweak, and CD30), LT alternative NF-KB pathway activation $[19,78]$. The activation of one or the other NF-KB signaling pathway is spatially and temporally regulated by LT $\beta R$ trafficking [19] and varying levels of receptor cross-linking may be required for distinct conformational changes and 
activation of different signal transduction pathways. Furthermore, the classical and the alternative NF-KB signaling pathways control distinct patterns of gene expression [78] and are therefore differentially involved in various functions attributed to LT $\beta R$ signaling (Figure 2).

To activate the classical NF-KB signaling pathway, LTRR engagement leads to TRAF2 recruitment to its $C D$ and subsequent IKK-mediated IKB $\alpha$ phosphorylation and degradation by the proteasome [79]. These events lead to p50-RelA heterodimer activation $[78,80]$. When upregulated, TRAF3 was shown to inhibit TRAF2 recruitment to LT $\beta R$, thus negatively regulating NF-KB activation [79]. When LIGHT or $L T \alpha_{1} \beta_{2}$ accumulates at the surface of LT $\beta R$-inducing cells, higher-order clusters of LT $\beta R$ may form on the target cell that seemingly trigger dynamin-2-dependent endocytosis of the receptor [19]. During this process, the LTRR CD was shown to remain exposed towards the cytosol and to compete with NIK for the binding of its inhibitory complex composed by TRAF3/TRAF2/cIAP1/cIAP2 $[81,82]$. As a consequence, the constitutive proteasomal degradation of NIK is alleviated, leading to NIK accumulation and activation of IKKa. These events lead to p100 processing to $p 52$ and the translocation of p52/RelB dimers to the nucleus (Figure 2) $[19,83]$. LT $\beta R$ mediated activation of alternative NF-KB signaling is terminated by a mechanism of negative feedback control relying on IKKa-dependent destabilization of NIK [84]. Thus, TRAF3 inhibits NF-KB signaling by being part of a complex that mediates NIK targeting to proteasome degradation and, thus inhibits the processing of p100 to p52 [79,85]. Regarding kinetics, ligand binding to LT $\beta R$ can induce a rapid and transient activation of the classical NF-KB pathway, followed by a delayed but sustained activation of the alternative pathway $[78,80]$. The delayed activation of the alternative pathway may be at least partially due to the requirement for increased $N f k b 2$ gene transcription (encoding $\mathrm{p} 100$ ), which is mediated by the IKK $\beta$-dependent classical pathway [78,80]. Alternatively, it was proposed that LT $\beta R$ activation induces the IKKa-dependent alternative pathway alone, resulting in p100 degradation and eventually activating RelA-containing and RelB-containing dimers [86]. Through the activation of p50/RelA heterodimers, LT $\beta R$ signaling promotes for instance the upregulation of proinflammatory molecules including the CCL4/macrophage inflammatory protein (MIP)-1 $\beta$, CXCL2/MIP-2 and vascular-cell adhesion molecule 1 (VCAM-1) in mouse embryonic fibroblasts (MEFs) [78], and CXCL1, CXCL2, intercellular adhesion molecule 1 (ICAM-1), VCAM-1, and E-selectin in endothelial cells [87]. Conversely, LTßR-mediated activation of $\mathrm{p} 52 / \mathrm{Re} \mathrm{B}$ heterodimers results in the production of lymphoid chemokines such as the CCL19/EBI1-ligand chemokine (ELC), CCL21/secondary lymphoid tissue chemokine

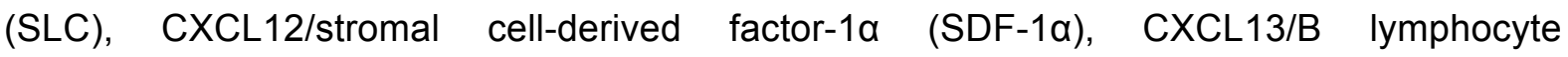
chemoattractant (BLC) and the cytokine B cell activation factor (BAFF), being all involved in lymphoid organogenesis and homeostasis $[26,78]$. 


\section{Physiological roles of lymphotoxin signaling}

LTa $\alpha_{1} \beta_{2} /$ LIGHT-induced LT $\beta R$ signaling is critically involved in lymphoid organogenesis and maintenance of secondary lymphoid structures, in addition to its roles in regulation of innate and adaptive immune response, inflammation, and tissue homeostasis.

Lymphoid organogenesis is largely associated with LT $\beta R$ signaling induced by the $\mathrm{LTa}_{1} \beta_{2}$ heterotrimer, as shown by studies blocking ligand-receptor interaction $[88,89]$ or using LT $\beta R$, LTa, LT $\beta$ or LIGHT knockout mice $[1-3,90]$. LT $\beta R$ knockout mice lack several secondary lymphoid organs, including peripheral and mesenteric lymph nodes (LNs), Peyer's patches and gut-associated lymphoid tissues (GALT) [1]. LTa knockout mice generally lack peripheral and mesenteric LNs and Peyer's patches, although mesenteric lymphoid aggregates were observed in a few mice [3,91]. LT $\beta$ knockout mice lack most LNs, but in contrast to LTa and LT $\beta$ R-deficient mice conserved fully organized mesenteric LNs and cervical lymph node-like structures [2,92]. Mesenteric LN development was impaired by simultaneous LT $\beta$ and LIGHT inactivation, meaning that LIGHT can compensate for LT $\beta$ absence in mesenteric LN development [90]. In addition, LTa-, LT $\beta$ - and LT $\beta R$-deficient mice, but not LIGHT-deficient mice presented splenic structural defects. Discrepancies in the effects of ligand-receptor gene inactivation led to the supposition, yet to be confirmed, that either an alternative unknown ligand for LT $\beta R$ or other nonspecific interactions could account for such phenotypic differences [1-3].

In the adult, LT $\beta R$ signaling was reported to be critically involved in the adaptive immune response against pathogens due to its intervention in processes such as DC homeostasis and expansion [93,94], and lymphocyte maturation and survival [95-98]. Furthermore, its activation is continuously required for the maintenance of the integrity and organization of microenvironments from secondary lymphoid organs $[1,88,89]$. For example, $L T \beta R$ is important for the development and structural maintenance of fibroblastic reticular cells (FRCs) in LNs and spleen [99,100]. In the spleen, LT $\beta R$ activation was also shown to be essential for FDC differentiation [101]. Accordingly, LT $\beta R$-deficient mice present disrupted FDC and germinal center formation and, consequently deficient B cell affinity maturation [1]. LT $\beta R$ signaling is also important for the trafficking of lymphoid and other hematopoietic cells, namely the recruitment, migration and organization inside organs, and the migration to other tissues $[4,26,42,102]$. Moreover, it is involved in the regulation of acute inflammatory reactions and in the development of inflammation-associated ectopic lymphoid structures $[41,103]$. In the latter process, LT $\beta R$-dependent stromal cell differentiation into reticular networks and induction of chemokines, cytokines and adhesion molecules play a 
critical role. Finally, LT $\beta$ R activation favors the recruitment of hematopoietic cells to lymphoid compartments by instructing the development and function of high endothelial venules (HEVs) [7,104].

Importantly, LT $\beta R$ signaling leading to NIK/IKKa-dependent alternative NF-KB activation has been shown to be a key player for thymic medullary epithelial cell differentiation [105] and the maintenance of the thymic structure [4], considered essential for central tolerance induction. In this context, $\mathrm{T}$ cell development and selection, and the maintenance of the thymic microenvironments require reciprocal interactions between thymocytes and stromal cells where LTRR signaling is a critical mediator of this thymic crosstalk [4]. In addition, cTEC cell death mediated by LT $\beta R$ and TNFR1 combined and NIK activation was proven essential for thymic involution in pathological conditions [75-77].

Although LTRR and its ligands are widely recognized as key players in immunity, they are also involved in many other biological processes such as liver regeneration $[5,106]$, hepatic lipid metabolism [6], and adipocyte differentiation [107]. Importantly, LTßR signaling has also been reported to be involved not only in cell death and tumor growth inhibition, but also in cancer development and progression $[15,16]$.

\section{LT $\beta R$ suppressor functions in solid tumors}

\subsection{LTRR activation leading to cancer cell death}

The lymphotoxin designation was first attributed upon LTa identification as a cytokine similar to TNFa that presented cytolytic/cytostatic effects on target cells [108]. Indeed, LT $\beta R$ activation was first shown to mediate cytotoxic effects in tumors, thus pointing to a potential anti-cancer therapy, especially because this receptor was found to be expressed in a wide range of tumor types $[65,70,73]$.

The direct anti-cell growth role of LT $\beta R$ has been demonstrated in a subset of human epithelial cancer cell lines (e.g., HT-29, WiDr, Hep3BT2, MCF-7, and HeLa), where LTßR activation was shown to induce death with slow kinetics (36-72 h) either in the presence of IFN-Y $[69,71]$ or through LT $\beta R$ ligand-independent self-association caused by overexpression [66]. Furthermore, LT $\beta R$ activation was reported to arrest tumor growth in mice xenografted with colorectal cancer cell lines and patient samples $[69,70]$. The molecular mechanism by which LTßR contributes to cancer cell line death has however remained elusive.

To study LT $\beta R$-induced anti-growth effects in cancer, Hu and coworkers used a lung experimental metastasis model in which mouse colon carcinoma cells were injected i.v. into BALB/c mice and found that $\mathrm{CD} 11 \mathrm{~b}^{+}$myeloid cells, NK cells, and $\mathrm{CD} 8^{+}$and $\mathrm{CD} 4^{+} \mathrm{T}$ cells 


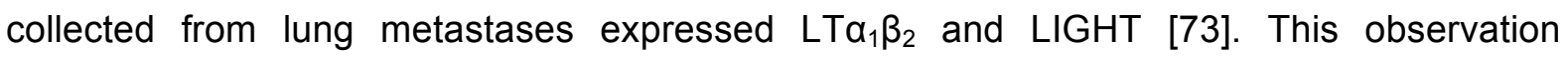
supported a previous report indicating that monoclonal antibody (mAb)-mediated LT $\beta R$ activation in established CT26 cell line-derived subcutaneous tumors led to both T cell infiltration, probably mediated by pro-inflammatory chemokines, and tumor necrosis [70]. Supporting the notion that immune cells interact with tumor cells through LT $\beta R$ to suppress spontaneous tumor development, recombinant $L T \alpha_{1} \beta_{2}$ and LIGHT proteins or an agonist $L T \beta R$ mAb could inhibit in vitro growth of human colon carcinoma and soft tissue sarcoma cell lines [73]. Likewise, using a syngeneic mouse model of sarcoma metastasis to the lung together with adoptive transfer of tumor-specific cytotoxic T lymphocytes (CTL), Yang and co-workers previously showed that LT $\beta R$ was a direct effector of CTL-mediated tumor rejection in vivo [109]. Regarding the mechanism, LT $\beta R$ stimulation by an agonistic mAb induced caspase- and mitochondrial-dependent apoptosis and activated classical and alternative NF-kB pathways in human cancer cell lines [73]. Furthermore, NF-kB inhibition promoted CT26 colon cancer cell metastatic potential in vivo, suggesting that in this context LT $\beta R$-mediated apoptosis and activation of the NF-KB signaling pathway might act in concert to suppress tumor development [73].

It has been suggested that $L T \alpha_{1} \beta_{2}$ and LIGHT ligand expression by immune cells such as T cells [109], NK cells [110] or DCs [111] may engage LT $\beta R$ on tumor cells and thus trigger antitumor cytotoxicity. Yet, tumor cell death in these studies was induced by recombinant ligands and/or LT $\beta R$ agonistic antibodies, which may not reflect the physiological levels and activity of ligands expressed at the surface of immune cells. This caveat is underscored by results showing that LT $\beta R$ activation and downstream signaling pathways induced in vitro by recombinant ligands or agonistic antibodies may depend on the duration and degree of receptor oligomerization [64]. Nevertheless, LTßR-mediated tumor suppression by either agonistic mAbs $[69,70]$ or adoptively transferred tumor-specific CTLs [109] was put forward as a therapeutic approach to halt tumor growth and to override colon carcinoma and soft tissue sarcoma chemo- and radiotherapy resistance $[70,73]$.

\subsection{LTRR or HVEM activation leading to immune-mediated tumor rejection}

\subsubsection{LIGHT-induced recruitment and activation of anti-tumoral lymphocytes}

Rather than identifying a direct effect of LT $\beta R$ signaling in tumor regression, Winter and coworkers found that LT $\beta R$-mediated tumor regression could occur through an indirect pathway [112]. These authors used an experimental pulmonary metastasis model generated by intravenous injection of the D5 melanoma cell line (a B16 cell line subclone) in syngeneic mice, and found that infiltrating effector T cells, which expressed LT $\beta R$ ligands, activated LT $\beta R$ but did not induce apoptosis of D5 tumor cells in vitro. Instead, LT $\beta R$ activation in D5 melanoma cells induced the secretion of chemokines that mediate macrophage migration 
[112]. Although, direct anti-tumor effects could not be excluded, this report indicates that $L T \beta R$ activation by $L T \alpha_{1} \beta_{2}$ and/or LIGHT is involved in the induction of chemotactic molecules that create a tumor microenvironment favorable for lymphocyte homing, which in turn may boost anti-tumor immunity and contribute to tumor suppression. Also in this context, $\mathrm{Yu}$ and colleagues disclosed a role for $\mathrm{LT} \beta R$ signaling in tumor immune rejection [113]. LIGHT overexpression in a fibrosarcoma cell line that was then subcutaneously inoculated in C3B6F1 mice induced LT $\beta R$-mediated CCL21 and MAdCAM-1 expression in tumor microenvironmental cells. This in turn led to CD8 naïve $T$ cell infiltration and activation, leading to the rejection of the established tumor. Furthermore, direct inoculation of LIGHT-expressing tumor cells in established non-LIGHT-expressing primary tumors led to their regression. Primary tumor rejection was also achieved when LIGHT-expressing tumor cells were inoculated in another subcutaneous site, indicating that LIGHT can generate a systemic immune response against distal tumors. These data support the rationale of using LIGHT-expressing tumor vaccines as a therapeutic tool [113]. In this line, other researchers genetically engineered attenuated Salmonella to express LIGHT and used it as a targeting vehicle for local expression of LIGHT in tumors. This approach led to LTRR and HVEMdependent inhibition of both primary and metastatic tumor growth in subcutaneously injected syngeneic immunocompetent mice [114]. LIGHT expression induced both $T$ and $B$ lymphocyte infiltration and production of the CXCL9 chemoattractant in subcutaneous tumors, but it remained to be established whether these two effects were causatively linked [114]. LIGHT expression was also found to be frequent in patient-derived metastatic melanoma cells and in melanoma cell line-derived microvesicles, and to be correlated with T-cell infiltration [115]. In addition, another approach based on LIGHT-expressing adenovirus was tested for local tumor treatment. These viruses initiated priming of tumorspecific $\mathrm{CD}^{+} \mathrm{T}$ cells directly in the primary tumor, followed by the exit of CTLs, which homed to distal tumors to elicit immune-mediated eradication of spontaneous metastases [116]. Several studies therefore indicate that LIGHT is a potent primer of T-cell responses that can counter tumor growth and that it can be used as a therapeutic tool.

\subsubsection{LTßR-mediated HEV differentiation and recruitment of anti-tumoral lymphocytes}

In addition to its role in chemokine production and chemoattraction, LT $\beta R$ activation was shown to correlate with lymphocyte extravasation through HEVs and tumor infiltration, thus leading to tumor regression [117,118]. HEVs are specialized postcapillary vessels of secondary lymphoid organs, also found in chronically inflamed non-lymphoid tissues [119] and tumors [120]. These vessels mediate the extravasation of naïve and central memory lymphocytes from the peripheral blood to lymphoid tissues to initiate immune responses [121], and express LT $\beta R$, which is required for HEV differentiation and function [7]. In this 
context, Martinet and coworkers have recently found that in human breast cancer, higher numbers of $L T \alpha_{1} \beta_{2}$-expressing DCs were correlated with increased HEV density and $T$ and B lymphocyte infiltration. Moreover, LT $\beta$ expression correlated with expression of chemokines associated with HEV-mediated lymphocyte extravasation (CCL19, CCL21 and CXCL13) [118]. Interestingly, these authors showed that the tumor HEV density was inversely correlated with breast cancer progression, from in situ ductal carcinoma to invasive ductal carcinoma, and found that high density of HEVs in breast tumors was correlated with a favorable prognosis [118]. These findings contradict the generally accepted assumption that tumor angiogenesis correlates with tumor progression and worse prognosis, and highlight the notion that different types of tumor blood vessels play distinct roles. A similar mechanism was also found in a mouse model of methylcholanthrene-induced fibrosarcoma, in which depletion of $\mathrm{T}$ regulatory cells (Tregs) led to HEV development, T-cell infiltration, LT $\alpha$ and LT $\beta$ upregulation and decreased tumor growth [117].

In summary, LT $\beta$ R can mediate anti-tumor effects by direct cytotoxicity (Figure 3A) but also by other indirect mechanisms, like tumor cell sensitization to chemotherapeutic agents and radiation [70]. Furthermore, LT $\beta R$ can stimulate host-mediated anti-tumor immune responses either by inducing the expression of pro-inflammatory cytokines and chemokines that chemoattract and activate lymphocytes [70,112] (Figure 3B), or by inducing the differentiation of HEVs that mediate lymphocyte trafficking to both normal organs and tumors $[7,118]$ (Figure 3C).

\section{LT $\beta$ R-mediated promotion of solid tumors}

In contrast to the previously discussed anti-cancer roles of LT $\beta R$, a tumor-promoting role for this receptor has been disclosed in a wide variety of contexts. Cancer cells from different origins express $\operatorname{LT} \beta R[65,70,73]$, being often this expression increasingly more prevalent with cancer progression and metastasis $[65,73,122]$. Furthermore, LTBR gene upregulation or structural alterations leading to $L T \beta R$ constitutive activation were reported to correlate with carcinogenesis [65,122-124] (Figure 4A). As shown below, LT $\beta R$ is thought to promote oncogenesis either by directly fostering survival and/or proliferation of malignant cells or by generating a pro-tumorigenic inflammatory microenvironment.

\section{1. $L T B R$ genetic alterations leading to $L T \beta R$ constitutive activation}

An early study reporting an LT $\beta R$ pro-tumorigenic role identified an $\mathrm{NH}$-terminally truncated form of $L T \beta R$ in a pancreatic ductal carcinoma cell line. This truncated receptor as well as the full-length LT $\beta R$ protein were shown to have fibroblast transforming activity in vitro and in vivo, even in the absence of their cognate ligands [123]. In another study, the 12p13.3 
region, including the $L T B R$ locus, was found to be in higher copy number in $51 \%$ and amplified in $7 \%$ of nasopharyngeal carcinoma (NPC) cases [122]. Additionally, LT $\beta R$ protein was found to be frequently overexpressed in NPC tumors. Subsequently, LT $\beta R$ overexpression in an immortalized nasopharyngeal epithelial cell line was shown to contribute to ligand-independent cell proliferation. Importantly, LT $\beta R$ knockdown inhibited in vivo tumor growth in an NPC xenograft mouse model [122]. Since LT activated NF-KB in nasopharyngeal cells [122], the same authors showed that in cases without evident $L T B R$ amplification genetic alterations affecting other NF-kB signaling regulators (TRAF3, TRAF2, NFKBIA, and A20/TNFAIP3) were present [125]. These results therefore support a role for LT $\beta R$-mediated NF-KB activation in NPC development.

The oncogenic potential of LT $\beta R$ has also been reported in melanoma. Dhawan and co-workers have shown that LT $\beta R$ expression is upregulated in human metastatic melanoma samples when compared to normal melanocytes and other melanoma lesions. In melanoma cell lines, LTßR activates the NF-KB pathway and induces cell proliferation and invasiveness, all in a ligand-independent manner [65]. These findings suggest that, like in pancreatic cancer, the elevated expression of $L T \beta R$ in melanoma is by itself sufficient to drive cancer progression.

\subsection{Ligand-dependent activation of $L T \beta R$ in cancer development}

Despite reports indicating that LT $\beta R$ signaling can be activated in the absence of ligands, other studies have shown that these may play important roles in promoting cancer. Genetic studies in humans identified single nucleotide polymorphisms (SNPs) in the LTa gene that may be either cancer-protective or lead to an increased cancer risk. For example, one common SNP, $L T A+252 A>G$ or rs909253, was described in meta-analysis studies to be positively associated with cancer susceptibility to different types of cancer $[126,127]$. Such susceptibility was also found for specific cancer types, such as non-Hodgkin lymphoma $[128,129]$, breast cancer $[130,131]$ and gastric cancer $[132,133]$. Despite conflicting data on the association between LTA gene polymorphisms and risk for different types of cancer in different ethnic populations, and on whether the polymorphic allele is present in homozygosity or heterozygosity, it was reported that different LTA alleles may result in differential gene transcription and protein expression [134,135]. Since LTa plays a key role in immunity and inflammation [136], alterations in its production may affect anti-cancer immunity and inflammation-induced cancer. Yet, the exact mechanism by which it affects cancer risk in each context remains to be defined. Furthermore, the involved LTa-containing ligand, either $\mathrm{LTa}_{3}$ homotrimer or $\mathrm{LTa}_{1} \beta_{2}$ heterotrimer, was not determined by these studies. 


\subsection{LTRR pro-oncogenic roles mediated by interactions with the tumor microenvironment}

Immune cells are the main source of LT $\beta R$ ligands and the interaction of these cells with tumor cells can either restrain, as discussed above, or promote tumor progression. Tumor and/or stromal cells respond to injury, infection and tissue stress by producing cytokines and chemokines that attract immune cells [137]. As a result, these cells migrate to the tumor microenvironment where they secrete inflammatory, pro-angiogenic and pro-tumorigenic factors that may affect tumor progression and metastasis. Thus, depending on the tumor microenvironment chemokine milieu, tumor-infiltrating immune cells can stimulate the immune response against tumor cells or rather help these to subvert the immune response and promote oncogenesis. As a signaling axis involved in immune cell communication, in addition to its involvement in the induction of tumor-suppressive microenvironments, as discussed above, LT $\beta R$ signaling can also contribute for the induction of pro-oncogenic, inflammatory microenvironments. A wide range of studies have shown that inflammation can promote tumorigenesis by promoting angiogenesis, release of growth and survival factors, invasiveness, metastasis and evasion of host defense mechanisms [138].

\subsubsection{LT $\beta R$-induced angiogenesis}

The importance of angiogenesis for the growth of solid tumors has since long been recognized. As tumor growth and metastasis require persistent new blood vessel formation, a developing tumor shifts from the avascular phase to the angiogenic phase, the so-called angiogenic switch [139]. This switch is controlled by a balance between pro- and antiangiogenic factors, which are secreted by the tumor cells themselves or by cells in the tumor microenvironment, in particular resident stromal cells and immune cells. It is known that the expression of pro- and anti-angiogenic factors by cancer cells can be controlled either directly by oncogenes, tumor suppressor genes and transcription factors or indirectly by extrinsic factors. Yet, the roles and the interplay among the various inflammatory cytokines and chemokines in the angiogenic switch are still poorly understood.

In this context, Hehlgans and co-workers have shown that inhibition of LTRR signaling can block angiogenesis and tumor growth [140,141]. Using methylcholanthreneinduced murine fibrosarcoma BFS-1 cells, these authors have shown that LTRR activation by $L T \alpha_{1} \beta_{2^{-}}$or LIGHT-expressing $T$ and $B$ lymphocytes induced the expression of the angiogenic mediator CXCL2 [140]. CXCL2 induction in BFS-1 cells depended on NF-KB activation and contributed for solid tumor growth in vivo. The described pro-tumorigenic effect was assumed to be due to the modulation of the tumor microenvironment through LT $\beta R$-mediated angiogenesis induction (Figure 4B) because LT $\beta R$ inhibition blocked BFS-1 tumor angiogenesis while direct LT $\beta R$ stimulation (with an agonistic anti-LT $\beta R$ monoclonal antibody) did not increase proliferation or survival of fibrosarcoma cells [141]. 


\subsubsection{LT $\beta R$-induced chronic inflammation}

Tumors often arise in sites of chronic inflammation [142], which provide a microenvironment containing various mediators (e.g., cytokines, chemokines, and prostaglandins) with tumorpromoting properties, including enhanced cell proliferation, survival, angiogenesis and migration. In this context, Haybaeck and co-workers have found the involvement of LT $\beta R$ signaling in the development of virus-induced chronic hepatitis and hepatocellular carcinoma (HCC) [13]. In hepatic primary tissue from hepatitis B or C (HBV- or HCV)-induced chronic hepatitis and HCC patients, these authors found upregulation of not only LT $\beta R$ and its ligands (LTa, LT $\beta$ and LIGHT) but also pro-inflammatory chemokines (CCL2, CCL3 and CXCL10). LTBR was highly expressed in liver cell populations depleted of hematopoietic (CD45-positive) cells, while $L T A, L T B$ and $L I G H T$ were expressed both in hematopoietic and non-hematopoietic HCV-induced hepatitis and $\mathrm{HCC}$ liver cell fractions. Furthermore, expression of $\angle T B R, \angle T A, \angle T B, L I G H T$ and inflammatory chemokines in a human hepatocyte cell line Huh-7.5 was shown to be directly linked to the presence of HCV infection. In transgenic mice expressing high levels of LTa and LT $\beta$ in a liver-specific manner, LT $\beta R$ signaling induced chronic hepatitis characterized by inflammation, $T$ and $B$ lymphocytic infiltrates and hepatocyte apoptosis. Further experiments demonstrated that $T$ and B cells, which express LT $\beta R$ ligands, and LT $\beta R$-mediated canonical NF-KB signaling activation in hepatocytes were both required for $L T \beta R$-induced chronic hepatitis and HCC development [13]. These findings indicate that persistent lymphocyte-derived $L T \alpha_{1} \beta_{2}$ and LT $\beta$ R-induced NF-KB activation are tumor-promoting, and that rather than having direct oncogenic properties, LT $\beta R$ signaling reshapes and generates an inflammatory, oncogenic hepatic microenvironment (Figure 4C). Interestingly, it was recently reported that short-term $L T \beta R$ stimulation led to degradation of HBV-derived covalently closed circular DNA (cccDNA) in infected hepatocytes [143]. This anti-HBV effect was shown to be mediated by $L T \beta R$-induced APOBEC3B deaminase expression and indicates that LT $\beta R$ agonists could be incorporated in anti-HBV combined therapeutic regimens [143]. Importantly, these data suggest that in contrast to the HCC-causing inflammation-related persistent LT $\beta R$ stimulation, transient stimulation may actually prevent HBV-induced HCC.

Supporting the aforementioned studies on hepatitis and HCC [13], Simonin et al. (2013) have shown in a recent report that LT $\beta$ expression can be induced by the HCV NS5B polymerase in a human hepatoma cell line. Using transgenic mice with hepatocyte-targeted expression of the entire ORF of the genotype $1 \mathrm{~b} \mathrm{HCV}$, Simonin and co-workers have also shown that LT $\beta$ hepatocyte expression in HCV transgenic liver tumors was associated with NF-KB activation, chemokine synthesis and intra-tumoral recruitment of macrophages and $T$ and $B$ lymphocytes [43]. In addition to these studies on viral-induced HCC, LT $\beta R$ was shown 
to be also involved in the pathogenesis of non-viral HCC. Using a mouse model of long-term choline-deficient high-fat diet, Wolf et al. (2014) identified $\mathrm{CD}^{+}{ }^{+}$cells and NKT cells recruited to the liver as key players in the development of steatosis and HCC. These cells were shown to interact with hepatocytes leading to their activation and to the release of soluble factors such as LIGHT and lymphotoxin. In addition, LT $\beta R$ and classical NF-KB signaling were shown to be activated in hepatocytes, thus facilitating liver tumorigenesis [144]. More recently, LT $\beta R$ signaling was found to participate in oncogene-driven HCC progression [145]. In an HCC mouse model initiated by constitutively active Akt (in combination with mutated $\beta$-catenin or Notch1), LT $\beta$ and LT $\beta R$ expression were found to be upregulated in liver tumors. More importantly, blockade of LT $\beta R$ signaling reduced tumor progression and prolonged mouse survival [145]. Together, these reports demonstrate that independently of the causing agent, LT $\beta R$ persistent signaling in the context of chronic inflammation promotes $\mathrm{HCC}$ progression, and may be a potential therapeutic target.

Cancer therapy-induced cell death can also elicit an inflammatory response that may contribute to therapeutic resistance. This is the case of castration-resistant metastatic prostate carcinoma, the emergence of which constitutes a major complication limiting the success of androgen ablation therapy and underlying most prostate cancer-associated mortality. Using two animal models, the SV40 large $T$ antigen-driven transgenic adenocarcinoma mouse prostate (TRAMP) cancer model and the mouse androgendependent CaP prostate cancer cell line subcutaneously allografted in castrated FVB mice, Ammirante et al. (2010) unveiled a mechanism underlying the emergence of castrationresistant prostate cancer. These researchers found that following androgen ablation therapies, the death of androgen-deprived primary cancer cells induced an inflammatory response with concomitant production of $\mathrm{CXCL} 13$ and other inflammatory chemokines, and recruitment of leukocytes, mostly $B$ cells, into the regressing tumor. IKK $\beta$ activation in $B$ cells, presumably by inflammatory cytokines, induced the expression of surface $L T \alpha_{1} \beta_{2}$ in these cells. These $L T \alpha_{1} \beta_{2}$-expressing $B$ cells led to LT $\beta R$ activation and IKKa nuclear translocation in prostate cancer cells to promote androgen-independent growth and survival [146].

A more recent study has shown that the endogenous "danger signal" HMGB1 protein was induced during prostate tumor progression in TRAMP mice, and that it was required for the infiltration and activation of $T$ cells (but not B cells) within the tumor [147]. Prostate tumor-infiltrating $T$ cells were shown to express $L T \alpha_{1} \beta_{2}$ and, through $L T \beta R$ activation in stromal cells, to promote the recruitment of tumor macrophages, presumably by inducing CCL2 expression. More importantly, LT $\beta R$ signaling was shown to facilitate progression from hyperplasia to invasive prostate carcinoma [147]. Considering these findings with those obtained by Ammirante et al. (2010), it can be concluded that LT $\beta R$ signaling may contribute 
to several phases of prostate oncogenesis, through different molecular mechanisms (CXCL13 or CCL2 production) and involving different cellular players (T or B lymphocytes), and may therefore be of therapeutic value.

\subsubsection{Induction of a pro-tumorigenic niche supported by LT $\beta R$-expressing stromal cells} $L T \beta R$ signaling has been implicated in other epithelial cancers, as for example ovarian cancer [148]. Lau and co-workers detected LTA and LTB overexpression in ovarian cancer cells and demonstrated that $L T \alpha_{1} \beta_{2}$-expressing human ovarian primary cancer cells induce LT $\beta R$-expressing cancer-associated fibroblasts (CAFs) to express chemokines through NF$\mathrm{KB}$ signaling. One of the chemokines identified as being induced in CAFs was CXCL11, which was able to promote proliferation and migration of CXCR3-expressing ovarian cancer cells [148]. Thus, in this setting cancer cells generate a pro-tumorigenic microenvironment through increased lymphotoxin expression and LT $\beta R$ activation in stromal cells.

\subsubsection{Immune evasion mediated by LT $\beta R$}

Another way by which LT $\beta R$ signaling is involved in cancer promotion is by dampening the host adaptive immune response to cancer. Because $L T \alpha_{1} \beta_{2}-L T \beta R$ signaling plays a role in immune self-tolerance due to its key role in medullary thymic epithelial cell development and function [4], blocking this signaling axis may rescue tumor-reactive effector $T$ cells from thymic clonal deletion and thus counter cancer development [149]. To test this hypothesis, Zhou et al. (2009) used the TRAMP animal model co-expressing a TCR specific for SV40 large $T$ antigen. Targeted mutation of the Lta gene was found to impair thymic negative selection of tumor-reactive T cells, resulting in decreased prostate cancer incidence and in milder malignant phenotype. Confirming the impact of LT $\beta R$ signaling in prostate oncogenesis, short-term LT $\beta R$ blockade in TRAMP mice rescued $T$ cells from clonal deletion, reduced the progression of primary prostate cancer and prevented metastasis [150]. This study thus suggests that LT $\beta R$ signaling may constitute a non-antigen-based strategy of immune cancer prevention potentially useful for patients with high genetic risk for prostate cancer. Another report has highlighted an alternative role for LT $\beta R$ in tumor immunoevasion. Kim and co-workers showed that the human papillomavirus 16 (HPV16) E6 oncogene induced LTa, LT $\beta$ and LT $\beta R$ expression in cervical cancer cell lines [44]. More importantly, LTßR signaling led to MHC class I downregulation in these cells and to resistance to cytotoxic $T$ lymphocyte-mediated lytic activity [44]. Whether such mechanism of cancer cell evasion from the host immune system takes place in vivo and results in tumor progression remains to be determined. 


\section{LT $\beta R$ role in hematological malignancies}

Several reports indicate that hematological malignancies are fostered by LT $\beta R$ signaling, either intrinsically to cancer cells or indirectly through microenvironmental cells. Studies aiming to identify genetic abnormalities underlying multiple myeloma pathogenesis identified alterations (e.g., deletions, amplifications, and point mutations) in several NF-KB regulators, in about $15 \%$ of patient samples and $30-40 \%$ of cell lines $[124,151]$. Such alterations included $L T B R$ amplification in one patient sample and one cell line [124]. Despite the low frequency of abnormalities in $L T B R$ and other functionally related genes, these studies indicated that constitutive activation of the LTRR-activated noncanonical NF-KB pathway promotes multiple myeloma oncogenesis [124].

$L T \alpha_{1} \beta_{2}-L T \beta R$ signaling has also been shown to mediate paracrine or juxtacrine tumor-stroma interactions leading to microenvironment modulation and establishment of chemoattractive tumor-permissive niches in secondary lymphoid organs (Figure 4D). Rehm and co-workers identified the homeostatic chemokine receptor CCR7 as a determinant factor in dictating the location and survival of B-cell lymphoma cells within secondary lymphoid organs [152]. Using the $E \mu-M y c$ transgenic mouse model of aggressive human Bcell lymphoma, these researchers found that CCR7 controls lymphoma cell dissemination to $L N s$ and to the splenic $T$-cell zone where, through $L T \alpha_{1} \beta_{2}$ expression, cancer cells stimulate

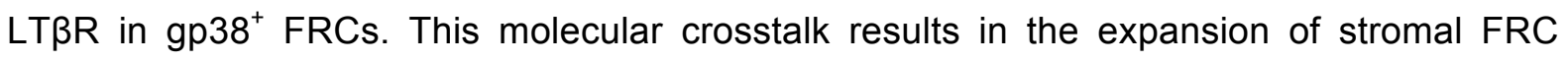
networks and release of chemoattractant homeostatic chemokines (e.g., the CCR7 ligands, CCL19 and CCL21) and trophic factors (e.g., IHH/indian hedgehog) that confer a survival advantage to lymphoma cells [152]. More recently, these authors used the murine $E \mu-T c / 1$ model of B-cell chronic lymphocytic leukemia to show that the CXCL13-CXCR5 signaling axis mediates leukemic $B$ cell access to a stromal compartment enriched with FDCs in splenic B cell follicles [153]. Here, leukemic B cells and FDCs engage in a reciprocal crosstalk in which $L T \alpha_{1} \beta_{2}$-expressing leukemic cells activate $L T \beta R$ and thus stimulate the differentiation of FDC networks and the production of CXCL13, CCL21, and other proproliferative and pro-survival growth factors [153]. In both studies, the inhibition of LT $\beta R$ mediated interactions between malignant and microenvironmental cells impaired disease progression and was therefore pointed as a possible strategy to complement standard cytotoxic therapies [152,153]. Recently, high expression of LTa and LT $\beta$-encoding genes was identified in human primary T-cell acute lymphoblastic leukemia expressing TAL or LMO oncogenes (TAL/LMO molecular subtype) [154]. Highlighting the relevance of these findings, $L T \beta R$ activation in thymic stromal cells was shown to promote T-cell leukemogenesis in a mouse model of T-cell acute leukemia/lymphoma [154]. Leukemic cells from these mice 
were shown to express high levels of LTa and LT $\beta$, from an early stage, and importantly, both early appearance of malignant cells and mouse survival were delayed in the absence of stromal LT $\beta R$. Since stromal cells dependent on RelB expression were shown be involved in mouse leukemogenesis [155], these studies support the notion that LT $\beta R$ activation in stromal cells promotes T-cell leukemogenesis through NF-KB activation.

\section{Signaling pathways mediating LT $\beta R$ activity in cancer}

As highlighted in the above sections, the classical or alternative NF-KB pathways appear to be the main mediators of most cellular events stemming from LT $\beta R$ signaling that contribute to its pro- and anti-oncogenic effects. However, a number of reports suggest that this is not always the case. In fact, some anti-oncogenic effects of LT $\beta R$ signaling leading to cancer cell death were reported to be mediated by other downstream components such as the reactive oxygen species-induced apoptosis signal-regulating kinase (ASK1) [72] and caspases (e.g., caspase 3 and 8 ) [66,71,73]. On the other hand, only few pro-tumorigenic effects of $L T \beta R$ signaling were found to result from activation of mediators other than NF-KB. Ammirante et al. (2010) reported that LT $\beta R$ activation in prostate carcinoma cells by lymphotoxin expressed on $B$ cells infiltrating regressing tumors after castration was required for IKKa translocation to the nucleus and STAT3 activation, nevertheless a collaboration with another unidentified critical cytokine/receptor activating STAT3 was predicted [146]. Although JNK has been shown to be activated by LTRR (Figure 2) and to be implicated in cancer, in promoting or suppressing it [156], no report has so far addressed whether this kinase is involved in cancer-related LT $\beta R$ activity.

\section{Signaling pathways with context-dependent outcomes in carcinogenesis}

Taken together, the aforementioned reports demonstrate the dual role of $L T \alpha_{1} \beta_{2} / L I G H T$ $L T \beta R$ signaling axis in cancer development. These proteins are not unique in that, other signaling proteins, such as tumor necrosis factor alpha (TNF $\alpha$ ), transforming growth factor beta (TGF $\beta$ ), NOTCH1 and NF-KB, share this context-dependent role in oncogenesis.

In accordance with its designation, TNF has been shown to induce apoptosis or necrosis in a variety of cancer cell types. TNF was shown to kill directly cancer cells [157], but its anti-oncogenic effects seem to involve mainly damage to the tumor vasculature through endothelial cell apoptosis $[158,159]$ and the stimulation of anti-tumoral immune responses [160-162]. In contrast to these findings, higher levels of TNFa were detected in 
the serum of cancer patients and in pre-neoplastic and tumor tissues, being associated with tumor progression [163-165]. Accordingly, in many studies, TNF was reported to prompt a broad range of pro-carcinogenic signaling mechanisms leading to tumor initiation and promotion (often in the context of chronic inflammation) including survival, proliferation, angiogenesis, invasion, and metastatic dissemination of cancer cells [166-170]. These contradictory roles in carcinogenesis seem to be associated with different tumor types and cellular contexts, and can be partly explained by levels of TNF production, chronic low doses leading to cancer development and progression and acute high doses leading to tumor regression [171].

TGF $\beta$ signaling is known to play dual roles in cancer [172-174]. In early stages of carcinogenesis, TGF $\beta$ mediates tumor-suppressing effects through cell-autonomous mechanisms, including suppression of cell proliferation and induction of apoptosis $[173,175]$. Supporting this tumor suppressive role of TGF $\beta$ signaling, genetic and epigenetic alterations attenuating or inactivating TGF $\beta$ receptors and downstream signaling components were reported in diverse types of cancer (reviewed in [175]). TGF $\beta$ was also shown to suppress oncogenesis indirectly by preventing the molecular crosstalk between TGF $\beta$ receptorexpressing stromal cells and cancer cells [176]. On the other hand, TGF $\beta$ can also promote tumor cell growth, invasiveness and metastasis in advanced tumors. Throughout tumor progression cancer cells dampen the growth-inhibitory TGF $\beta$ response, while its production increases in the tumor microenvironment [177]. As a consequence, by mechanisms such as increased chemokine expression and inflammation, immune response evasion, sustained angiogenesis, and epithelial-mesenchymal transitions (EMT) TGF $\beta$ leads to enhanced invasiveness and metastasis [177-180]. Therefore, the role played by TGF $\beta$ signaling likely depends on cancer type and cellular context. However, unlike LT $\beta R$ signaling, TGF $\beta$ tumorsuppressing or -promoting effects appear to rely on the stage of tumor development.

Notch signaling was also reported to mediate contradictory effects on oncogenesis. Activating mutations were identified in $\mathrm{NOTCH} 1$ and $\mathrm{NOTCH} 2$ genes in hematological malignancies (T-cell acute lymphoblastic leukemia, chronic lymphocytic leukemia, mantle cell lymphoma, and marginal cell lymphoma) and in breast adenocarcinoma [181-186]. Although the mechanisms are not fully understood, Myc induction seems to be a common downstream target in these different tumor contexts [187]. More recently, evidence was gathered indicating that $\mathrm{NOTCH} 1$ and $\mathrm{NOTCH} 2$ can also act as a tumor-suppressor gene in malignancies where inactivating mutations were detected. These included squamous cell carcinomas from skin, head and neck and lung [188-190] and chronic myelomonocytic leukemia [191]. In addition, NOTCH1 protein expression was found to mediate acute myeloid leukemia growth arrest and apoptosis [192,193]. The mechanisms remain to be identified but likely involve the resulting impaired activation of targets mediating pro- 
differentiation and anti-growth effects, and the promotion of an inflammatory state caused by Notch loss-of-function [187,194].

Interestingly, the main signaling pathway downstream LT $\beta R$ activation, that leading to NF-KB activation, has also been recognized to have opposing effects in cancer development. Although mutations affecting NF-KB and inhibitors of IKB kinase $\beta$ (IKK) are rarely found in human cancer, NF-KB subunits are frequently activated, resulting from either the induction of upstream pathways or loss of negative feedback mechanisms. Regardless of the causes of NF-kB aberrant activation, these transcription factors play prominent tumorpromoting roles, intrinsic, by rendering cancer cells resistant to apoptosis and/or highly proliferative, and extrinsic, by stimulating neoangiogenesis and inducing pro-invasive/prometastatic inflammatory microenvironments [195]. Contrasting with a large body evidence supporting their pro-oncogenic action, some reports have revealed an unexpected tumor suppressor role for NF-KB proteins in essentially two types of scenario. First, NF-KB exhibits tumor suppressor activity when acting in concert with well-characterized tumor suppressors, like p53 and ARF. These tumor suppressors bind NF-KB subunits to repress the potentially tumorigenic genes normally induced by NF-KB activation, most likely in an early stage of cancer development before cancer cells undergo loss of the implicated tumor-suppressor genes [196,197]. Second, in contexts where pro-survival signals derive from other oncogenes, NF-kB activation may enhance cytotoxic drug-mediated senescence in tumors, thereby exerting a tumor suppressor function [198,199]. Therefore, the NF-KB role in carcinogenesis is highly dependent on the tumor stage, tumor type, and presence of specific genetic alterations.

\section{Conclusions}

Since the discovery of the lymphotoxin signaling system, several researchers have investigated its role in cancer, including solid and hematological malignancies. As discussed in this review, early studies have uncovered a potential anti-tumoral role in several cancer types (Table 1). LTa $\beta_{1} \beta_{2^{-}}$and/or LIGHT-induced activation of LT $\beta R$ in a subset of solid cancers was reported to promote direct cytotoxic effects (Figure $3 \mathrm{~A}$ ) and/or indirect effects involving alterations in the tumor microenvironment (e.g., induction of chemokine expression and development of $\mathrm{HEV}$ ), which lead to increased anti-tumoral immune response (Figure $3 B, C)$. These reports disclosed a role for acute LT $\beta R$ activation in anti-cancer immunity and so this was suggested as a potential therapeutic approach. Conversely, during the last decade, several studies provided firm evidence that LT $\beta R$ signaling can promote both solid 
and hematological malignancy carcinogenesis. In some instances pro-oncogenic LT $\beta R$ signaling is intrinsic to cancer cells, in others it acts in tumor-promoting microenvironmental cells (Table 2). In the first setting, LT $\beta R$ signaling can be activated either independently of ligand binding due to $L T B R$ gene amplification or other molecular events leading to LT $\beta R$ overexpression (Figure $4 A$ ), or by increased expression of $L T \alpha_{1} \beta_{2}$ and/or LIGHT in the microenvironment (Figure $4 B$ and $C$ ). In the latter situation, LT $\beta R$ signaling in cancer cells leads to the secretion of factors (e.g., homeostatic chemokines and cytokines) that stimulate angiogenesis (Figure 4B) and/or attract infiltrating tumor-promoting immune cells (Figure 4C) thus stimulating cancer progression. Finally, in the setting where $L T \alpha_{1} \beta_{2}$-expressing cancer cells activate LT $\beta R$ in stromal cells, the latter can secrete chemokines or potentially other factors that favor cancer progression (Figure 4D). The role of infiltrating immune cells is rather complex, since in some contexts these can impair tumor progression through induction of host-mediated immunological responses as discussed above, while in other contexts they support tumor development by upregulating pro-inflammatory cytokines and by modulating the microenvironment. The balance between tumor-suppressing and tumorpromoting immune cell activity most likely depends on tumor stage, on the nature of recruited cells and on the type of factors produced by the tumor microenvironment.

Altogether, the reports previously cited have disclosed several factors influencing the pro- or anti-oncogenic activities of LT $\beta R$ signaling. Several variables such as the tumor type, the progression stage, the cancer-intrinsic genetic and epigenetic alterations, the status of activated signaling pathways, the microenvironmental factors, and the experimental model used may ultimately determine if the overall effect of LT $\beta R$ activation is pro- or antitumorigenic. Moreover, the mechanisms by which LT $\beta R$ may foster or counter tumor progression are not completely understood. Nevertheless, the classical and alternative NF$K B$ signaling pathways are both activated by LT $\beta R$ in all scenarios, which corroborates the dual role of NF-kB signaling observed in different cancer contexts [195].

Another important issue to consider when studying LTRR role in carcinogenesis is the mechanism of activation. It may be constitutively activated due to overexpression and self-oligomerization, or it may be activated only in the presence of its ligands. In the latter case, heterotypic interactions with cells present in the tumor microenvironment are usually involved. Furthermore, it is important to determine which $L T \beta R$ ligand is involved, if $L T \alpha_{1} \beta_{2}$, LIGHT, or both. Importantly, how ligand-induced activation of LTßR is achieved (e.g., membrane-bound or soluble ligand) or experimentally mimicked (e.g., lymphoid cells expressing the ligand, recombinant soluble ligand, or soluble or immobilized agonistic LT $\beta R$ antibody) should be carefully considered, since they may lead to different cellular outcomes. For instance, it was reported that the degree of receptor clustering and the varying lifetime of the oligomerized states may lead to diverse cellular responses following receptor activation 
$[21,64,69]$. Moreover, during the course of LTRR stimulation, which may be short or prolonged, different NF-KB complexes are activated and may result in the expression of different sets of target genes $[78,80]$.

Considering the described LT $\beta R$ pro-oncogenic functions and the notion that this receptor is most often activated by ligand binding, blockade of LT $\beta R$ signaling and interruption of crosstalk between tumor and microenvironmental cells has been proposed as a therapeutic approach [200]. Because of the dual functions of LT $\beta R$ in cancer development and progression, it is imperative to learn more about the mechanisms and contexts in which $L T \beta R$ may exert pro-oncogenic effects, and thus pave the way for the development of rational and more effective cancer therapies.

\section{Acknowledgments}

The authors thank Anna Hupalowska for assistance with illustrations. This work was supported by grants from Fundação para a Ciência e a Tecnologia (PTDC/SAUOBD/103336/2008 and PEst-OE/EQB/LA0023/2013), Núcleo Regional Sul da Liga Portuguesa Contra o Cancro (NRS/LPCC-Terry Fox), and Fundação MSD to N.R.d.S; Plan Cancer Action 29 and IAP7/32 (Belgium) to E.D.. M.T.F. is a recipient of a FCT PhD fellowship (SFRH/BD/75137/2010). N.R.d.S. has been supported by FCT Ciência 2007 and FCT Investigator contracts. 


\section{References}

[1] A. Fütterer, K. Mink, A. Luz, M.H. Kosco-Vilbois, K. Pfeffer, The lymphotoxin beta receptor controls organogenesis and affinity maturation in peripheral lymphoid tissues, Immunity. 9 (1998) 59-70.

[2] P.A. Koni, R. Sacca, P. Lawton, J.L. Browning, N.H. Ruddle, R.A. Flavell, Distinct roles in lymphoid organogenesis for lymphotoxins alpha and beta revealed in lymphotoxin beta-deficient mice, Immunity. 6 (1997) 491-500.

[3] P. De Togni, J. Goellner, N.H. Ruddle, P.R. Streeter, A. Fick, S. Mariathasan, et al., Abnormal development of peripheral lymphoid organs in mice deficient in lymphotoxin, Science. 264 (1994) 703-707.

[4] T. Boehm, S. Scheu, K. Pfeffer, C.C. Bleul, Thymic medullary epithelial cell differentiation, thymocyte emigration, and the control of autoimmunity require lymphoepithelial cross talk via LTbetaR, J. Exp. Med. 198 (2003) 757-769.

[5] A.V. Tumanov, E.P. Koroleva, P.A. Christiansen, M.A. Khan, M.J. Ruddy, B. Burnette, et al., T cell-derived lymphotoxin regulates liver regeneration, Gastroenterology. 136 (2009) 694-704.e4.

[6] J.C. Lo, Y. Wang, A.V. Tumanov, M. Bamji, Z. Yao, C.A. Reardon, et al., Lymphotoxin beta receptor-dependent control of lipid homeostasis, Science. 316 (2007) 285-288.

[7] J.L. Browning, N. Allaire, A. Ngam-Ek, E. Notidis, J. Hunt, S. Perrin, et al., Lymphotoxin-beta receptor signaling is required for the homeostatic control of HEV differentiation and function, Immunity. 23 (2005) 539-550.

[8] D. Hu, S.K. Mohanta, C. Yin, L. Peng, Z. Ma, P. Srikakulapu, et al., Artery Tertiary Lymphoid Organs Control Aorta Immunity and Protect against Atherosclerosis via Vascular Smooth Muscle Cell Lymphotoxin $\beta$ Receptors, Immunity. 42 (2015) 11001115.

[9] V. Bekiaris, J.R. Šedy, M. Rossetti, R. Spreafico, S. Sharma, A. Rhode-Kurnow, et al., Human CD4+CD3- innate-like T cells provide a source of TNF and lymphotoxin- $\alpha \beta$ and are elevated in rheumatoid arthritis, J. Immunol. 191 (2013) 4611-4618.

[10] J. Young, X. Yu, K. Wolslegel, A. Nguyen, C. Kung, E. Chiang, et al., Lymphotoxinalphabeta heterotrimers are cleaved by metalloproteinases and contribute to synovitis in rheumatoid arthritis, Cytokine. 51 (2010) 78-86.

[11] M.K. Gatumu, K. Skarstein, A. Papandile, J.L. Browning, R.A. Fava, A.I. Bolstad, Blockade of lymphotoxin-beta receptor signaling reduces aspects of Sjögren's syndrome in salivary glands of non-obese diabetic mice, Arthritis Res. Ther. 11 (2009) R24.

[12] G.M. Seleznik, J. Zoller, T. O'Connor, R. Graf, M. Heikenwalder, The role of lymphotoxin signaling in the development of autoimmune pancreatitis and associated secondary extra-pancreatic pathologies, Cytokine Growth Factor Rev. 25 (2014) 125137.

[13] J. Haybaeck, N. Zeller, M.J. Wolf, A. Weber, U. Wagner, M.O. Kurrer, et al., A lymphotoxin-driven pathway to hepatocellular carcinoma, Cancer Cell. 16 (2009) 295308.

[14] P. Stopfer, D.N. Männel, T. Hehlgans, Lymphotoxin-beta receptor activation by activated $\mathrm{T}$ cells induces cytokine release from mouse bone marrow-derived mast cells, J. Immunol. 172 (2004) 7459-7465.

[15] M.S. Drutskaya, G.A. Efimov, A.A. Kruglov, D.V. Kuprash, S.A. Nedospasov, Tumor necrosis factor, lymphotoxin and cancer, IUBMB Life. 62 (2010) 283-289.

[16] M.J. Wolf, G.M. Seleznik, N. Zeller, M. Heikenwalder, The unexpected role of lymphotoxin beta receptor signaling in carcinogenesis: from lymphoid tissue formation to liver and prostate cancer development, Oncogene. 29 (2010) 5006-5018.

[17] P.D. Crowe, T.L. VanArsdale, B.N. Walter, C.F. Ware, C. Hession, B. Ehrenfels, et al., A lymphotoxin-beta-specific receptor, Science. 264 (1994) 707-710. 
[18] W.R. Force, B.N. Walter, C. Hession, R. Tizard, C.A. Kozak, J.L. Browning, et al., Mouse lymphotoxin-beta receptor. Molecular genetics, ligand binding, and expression, J. Immunol. 155 (1995) 5280-5288.

[19] C. Ganeff, C. Remouchamps, L. Boutaffala, C. Benezech, G. Galopin, S. Vandepaer, et al., Induction of the alternative NF-kB pathway by lymphotoxin $\alpha \beta$ (LTa $\alpha$ ) relies on internalization of LT $\beta$ receptor, Mol. Cell. Biol. 31 (2011) 4319-4334.

[20] J. Kuai, E. Nickbarg, J. Wooters, Y. Qiu, J. Wang, L.-L. Lin, Endogenous association of TRAF2, TRAF3, CIAP1, and Smac with lymphotoxin beta receptor reveals a novel mechanism of apoptosis, J. Biol. Chem. 278 (2003) 14363-14369.

[21] T.L. VanArsdale, S.L. VanArsdale, W.R. Force, B.N. Walter, G. Mosialos, E. Kieff, et al., Lymphotoxin-beta receptor signaling complex: role of tumor necrosis factor receptor-associated factor 3 recruitment in cell death and activation of nuclear factor kappaB, Proc. Natl. Acad. Sci. U. S. A. 94 (1997) 2460-2465.

[22] M. Krajewska, S. Krajewski, J.M. Zapata, T. Van Arsdale, R.D. Gascoyne, K. Berern, et al., TRAF-4 expression in epithelial progenitor cells. Analysis in normal adult, fetal, and tumor tissues, Am. J. Pathol. 152 (1998) 1549-1561.

[23] H. Nakano, H. Oshima, W. Chung, L. Williams-Abbott, C.F. Ware, H. Yagita, et al., TRAF5, an activator of NF-kappaB and putative signal transducer for the lymphotoxinbeta receptor, J. Biol. Chem. 271 (1996) 14661-14664.

[24] W.R. Force, A.A. Glass, C.A. Benedict, T.C. Cheung, J. Lama, C.F. Ware, Discrete signaling regions in the lymphotoxin-beta receptor for tumor necrosis factor receptorassociated factor binding, subcellular localization, and activation of cell death and NFkappaB pathways, J. Biol. Chem. 275 (2000) 11121-11129.

[25] M. Murphy, B.N. Walter, L. Pike-Nobile, N.A. Fanger, P.M. Guyre, J.L. Browning, et al., Expression of the lymphotoxin beta receptor on follicular stromal cells in human lymphoid tissues, Cell Death Differ. 5 (1998) 497-505.

[26] N. Seach, T. Ueno, A.L. Fletcher, T. Lowen, M. Mattesich, C.R. Engwerda, et al., The lymphotoxin pathway regulates Aire-independent expression of ectopic genes and chemokines in thymic stromal cells, J. Immunol. 180 (2008) 5384-5392.

[27] J.L. Browning, I.D. Sizing, P. Lawton, P.R. Bourdon, P.D. Rennert, G.R. Majeau, et al., Characterization of lymphotoxin-alpha beta complexes on the surface of mouse lymphocytes, J. Immunol. 159 (1997) 3288-3298.

[28] D.N. Mauri, R. Ebner, R.I. Montgomery, K.D. Kochel, T.C. Cheung, G.L. Yu, et al., LIGHT, a new member of the TNF superfamily, and lymphotoxin alpha are ligands for herpesvirus entry mediator, Immunity. 8 (1998) 21-30.

[29] C.F. Ware, P.D. Crowe, M.H. Grayson, M.J. Androlewicz, J.L. Browning, Expression of surface lymphotoxin and tumor necrosis factor on activated $T, B$, and natural killer cells, J. Immunol. 149 (1992) 3881-3888.

[30] J.L. Browning, A. Ngam-ek, P. Lawton, J. DeMarinis, R. Tizard, E.P. Chow, et al., Lymphotoxin beta, a novel member of the TNF family that forms a heteromeric complex with lymphotoxin on the cell surface, Cell. 72 (1993) 847-856.

[31] P. Lawton, J. Nelson, R. Tizard, J.L. Browning, Characterization of the mouse lymphotoxin-beta gene, J. Immunol. 154 (1995) 239-246.

[32] S.A. Nedospasov, B. Hirt, A.N. Shakhov, V.N. Dobrynin, E. Kawashima, R.S. Accolla, et al., The genes for tumor necrosis factor (TNF-alpha) and lymphotoxin (TNF-beta) are tandemly arranged on chromosome 17 of the mouse, Nucleic Acids Res. 14 (1986) 7713-7725.

[33] G.E. Nedwin, S.L. Naylor, A.Y. Sakaguchi, D. Smith, J. Jarrett-Nedwin, D. Pennica, et al., Human lymphotoxin and tumor necrosis factor genes: structure, homology and chromosomal localization, Nucleic Acids Res. 13 (1985) 6361-6373.

[34] M.J. Eck, M. Ultsch, E. Rinderknecht, A.M. de Vos, S.R. Sprang, The structure of human lymphotoxin (tumor necrosis factor-beta) at 1.9-A resolution, J. Biol. Chem. 267 (1992) 2119-2122.

[35] L. Williams-Abbott, B.N. Walter, T.C. Cheung, C.R. Goh, A.G. Porter, C.F. Ware, The lymphotoxin-alpha (LTalpha) subunit is essential for the assembly, but not for the 
receptor specificity, of the membrane-anchored LTalpha1beta2 heterotrimeric ligand, J. Biol. Chem. 272 (1997) 19451-19456.

[36] M.J. Androlewicz, J.L. Browning, C.F. Ware, Lymphotoxin is expressed as a heteromeric complex with a distinct 33-kDa glycoprotein on the surface of an activated human T cell hybridoma, J. Biol. Chem. 267 (1992) 2542-2547.

[37] J.L. Browning, I. Dougas, A. Ngam-ek, P.R. Bourdon, B.N. Ehrenfels, K. Miatkowski, et al., Characterization of surface lymphotoxin forms. Use of specific monoclonal antibodies and soluble receptors, J. Immunol. 154 (1995) 33-46.

[38] D.V. Kuprash, V.E. Boitchenko, F.O. Yarovinsky, N.R. Rice, A. Nordheim, A. Rühlmann, et al., Cyclosporin A blocks the expression of lymphotoxin alpha, but not lymphotoxin beta, in human peripheral blood mononuclear cells, Blood. 100 (2002) 1721-1727.

[39] I. Millet, N.H. Ruddle, Differential regulation of Iymphotoxin (LT), lymphotoxin-beta (LT-beta), and TNF-alpha in murine T cell clones activated through the TCR, J. Immunol. 152 (1994) 4336-4346.

[40] C. De Trez, K. Schneider, K. Potter, N. Droin, J. Fulton, P.S. Norris, et al., The inhibitory HVEM-BTLA pathway counter regulates lymphotoxin receptor signaling to achieve homeostasis of dendritic cells, J. Immunol. 180 (2008) 238-248.

[41] T. Cupedo, W. Jansen, G. Kraal, R.E. Mebius, Induction of secondary and tertiary lymphoid structures in the skin, Immunity. 21 (2004) 655-667.

[42] S.A. Luther, A. Bidgol, D.C. Hargreaves, A. Schmidt, Y. Xu, J. Paniyadi, et al., Differing activities of homeostatic chemokines CCL19, CCL21, and CXCL12 in lymphocyte and dendritic cell recruitment and Iymphoid neogenesis, J. Immunol. 169 (2002) 424-433.

[43] Y. Simonin, S. Vegna, L. Akkari, D. Grégoire, E. Antoine, J. Piette, et al., Lymphotoxin signaling is initiated by the viral polymerase in HCV-linked tumorigenesis, PLoS Pathog. 9 (2013) e1003234.

[44] D.-H. Kim, E.-M. Kim, E.-H. Lee, K.-Y. Ji, J. Yi, M. Park, et al., Human papillomavirus 16E6 suppresses major histocompatibility complex class I by upregulating lymphotoxin expression in human cervical cancer cells, Biochem. Biophys. Res. Commun. 409 (2011) 792-798.

[45] S.W. Granger, K.D. Butrovich, P. Houshmand, W.R. Edwards, C.F. Ware, Genomic characterization of LIGHT reveals linkage to an immune response locus on chromosome 19p13.3 and distinct isoforms generated by alternate splicing or proteolysis, J. Immunol. 167 (2001) 5122-5128.

[46] K. Misawa, T. Nosaka, T. Kojima, M. Hirai, T. Kitamura, Molecular cloning and characterization of a mouse homolog of human TNFSF14, a member of the TNF superfamily, Cytogenet. Cell Genet. 89 (2000) 89-91.

[47] K. Tamada, K. Shimozaki, A.I. Chapoval, Y. Zhai, J. Su, S.F. Chen, et al., LIGHT, a TNF-like molecule, costimulates $T$ cell proliferation and is required for dendritic cellmediated allogeneic T cell response, J. Immunol. 164 (2000) 4105-4110.

[48] Y. Zhai, R. Guo, T.L. Hsu, G.L. Yu, J. Ni, B.S. Kwon, et al., LIGHT, a novel ligand for lymphotoxin beta receptor and TR2/HVEM induces apoptosis and suppresses in vivo tumor formation via gene transfer, J. Clin. Invest. 102 (1998) 1142-1151.

[49] O. Cohavy, J. Zhou, C.F. Ware, S.R. Targan, LIGHT is constitutively expressed on T and NK cells in the human gut and can be induced by CD2-mediated signaling, J. Immunol. 174 (2005) 646-653.

[50] C. Bossen, K. Ingold, A. Tardivel, J.-L. Bodmer, O. Gaide, S. Hertig, et al., Interactions of tumor necrosis factor (TNF) and TNF receptor family members in the mouse and human, J. Biol. Chem. 281 (2006) 13964-13971.

[51] D.D. Chaplin, Y. Fu, Cytokine regulation of secondary lymphoid organ development, Curr. Opin. Immunol. 10 (1998) 289-297.

[52] B.S. Kwon, K.B. Tan, J. Ni, K.O. Oh, Z.H. Lee, K.K. Kim, et al., A newly identified member of the tumor necrosis factor receptor superfamily with a wide tissue 
distribution and involvement in lymphocyte activation, J. Biol. Chem. 272 (1997) $14272-14276$.

[53] K.Y. Yu, B. Kwon, J. Ni, Y. Zhai, R. Ebner, B.S. Kwon, A newly identified member of tumor necrosis factor receptor superfamily (TR6) suppresses LIGHT-mediated apoptosis, J. Biol. Chem. 274 (1999) 13733-13736.

[54] M. Pierer, F. Brentano, J. Rethage, U. Wagner, H. Hantzschel, R.E. Gay, et al., The TNF superfamily member LIGHT contributes to survival and activation of synovial fibroblasts in rheumatoid arthritis, Rheumatol. 46 (2007) 1063-1070.

[55] T.L. Murphy, K.M. Murphy, Slow down and survive: Enigmatic immunoregulation by BTLA and HVEM, Annu. Rev. Immunol. 28 (2010) 389-411.

[56] T.C. Cheung, M.W. Steinberg, L.M. Oborne, M.G. Macauley, S. Fukuyama, H. Sanjo, et al., Unconventional ligand activation of herpesvirus entry mediator signals cell survival, Proc. Natl. Acad. Sci. U. S. A. 106 (2009) 6244-6249.

[57] Y. Morel, J.M. Schiano de Colella, J. Harrop, K.C. Deen, S.D. Holmes, T.A. Wattam, et al., Reciprocal expression of the TNF family receptor herpes virus entry mediator and its ligand LIGHT on activated T cells: LIGHT down-regulates its own receptor, J. Immunol. 165 (2000) 4397-4404.

[58] G. Shi, H. Luo, X. Wan, T.W. Salcedo, J. Zhang, J. Wu, Mouse T cells receive costimulatory signals from LIGHT, a TNF family member, Blood. 100 (2002) 32793286.

[59] X. Wan, J. Zhang, H. Luo, G. Shi, E. Kapnik, S. Kim, et al., A TNF family member LIGHT transduces costimulatory signals into human T cells, J. Immunol. 169 (2002) 6813-6821.

[60] D.W. Banner, A. D'Arcy, W. Janes, R. Gentz, H.J. Schoenfeld, C. Broger, et al., Crystal structure of the soluble human $55 \mathrm{kd}$ TNF receptor-human TNF beta complex: implications for TNF receptor activation, Cell. 73 (1993) 431-445.

[61] J. Sudhamsu, J. Yin, E.Y. Chiang, M.A. Starovasnik, J.L. Grogan, S.G. Hymowitz, Dimerization of LT $\beta R$ by LTa1 $\beta 2$ is necessary and sufficient for signal transduction, Proc. Natl. Acad. Sci. U. S. A. 110 (2013) 19896-19901.

[62] J. Eldredge, S. Berkowitz, A.F. Corin, E.S. Day, D. Hayes, W. Meier, et al., Stoichiometry of LTbetaR binding to LIGHT, Biochemistry (Mosc.). 45 (2006) 1011710128.

[63] P.S. Norris, C.F. Ware, The LT beta R signaling pathway, Adv. Exp. Med. Biol. 597 (2007) 160-172.

[64] F. Mackay, G.R. Majeau, P.S. Hochman, J.L. Browning, Lymphotoxin beta receptor triggering induces activation of the nuclear factor kappaB transcription factor in some cell types, J. Biol. Chem. 271 (1996) 24934-24938.

[65] P. Dhawan, Y. Su, Y.M. Thu, Y. Yu, P. Baugher, D.L. Ellis, et al., The lymphotoxinbeta receptor is an upstream activator of NF-kappaB-mediated transcription in melanoma cells, J. Biol. Chem. 283 (2008) 15399-15408.

[66] M.Y. Wu, P.Y. Wang, S.H. Han, S.L. Hsieh, The cytoplasmic domain of the lymphotoxin-beta receptor mediates cell death in HeLa cells, J. Biol. Chem. 274 (1999) 11868-11873.

[67] Y.-H. Chang, S.-L. Hsieh, M.-C. Chen, W.-W. Lin, Lymphotoxin beta receptor induces interleukin 8 gene expression via NF-kappaB and AP-1 activation, Exp. Cell Res. 278 (2002) 166-174.

[68] Y.-S. Kim, S.A. Nedospasov, Z.-G. Liu, TRAF2 plays a key, nonredundant role in LIGHT-lymphotoxin beta receptor signaling, Mol. Cell. Biol. 25 (2005) 2130-2137.

[69] J.L. Browning, K. Miatkowski, I. Sizing, D. Griffiths, M. Zafari, C.D. Benjamin, et al., Signaling through the lymphotoxin beta receptor induces the death of some adenocarcinoma tumor lines, J. Exp. Med. 183 (1996) 867-878.

[70] M. Lukashev, D. LePage, C. Wilson, V. Bailly, E. Garber, A. Lukashin, et al., Targeting the lymphotoxin-beta receptor with agonist antibodies as a potential cancer therapy, Cancer Res. 66 (2006) 9617-9624. 
[71] M.C. Chen, T.L. Hsu, T.Y. Luh, S.L. Hsieh, Overexpression of bcl-2 enhances LIGHTand interferon-gamma -mediated apoptosis in Hep3BT2 cells, J. Biol. Chem. 275 (2000) 38794-38801.

[72] M.-C. Chen, M.-J. Hwang, Y.-C. Chou, W.-H. Chen, G. Cheng, H. Nakano, et al., The role of apoptosis signal-regulating kinase 1 in lymphotoxin-beta receptor-mediated cell death, J. Biol. Chem. 278 (2003) 16073-16081.

[73] X. Hu, M.A. Zimmerman, K. Bardhan, D. Yang, J.L. Waller, G.B. Liles, et al., Lymphotoxin $\beta$ receptor mediates caspase-dependent tumor cell apoptosis in vitro and tumor suppression in vivo despite induction of NF-kB activation, Carcinogenesis. 34 (2013) 1105-1114.

[74] C.A. Wilson, J.L. Browning, Death of HT29 adenocarcinoma cells induced by TNF family receptor activation is caspase-independent and displays features of both apoptosis and necrosis, Cell Death Differ. 9 (2002) 1321-1333.

[75] M. Heikenwalder, M. Prinz, N. Zeller, K.S. Lang, T. Junt, S. Rossi, et al., Overexpression of lymphotoxin in T cells induces fulminant thymic involution, Am. J. Pathol. 172 (2008) 1555-1570.

[76] D.J. Liepinsh, A.A. Kruglov, A.R. Galimov, A.N. Shakhov, Y.V. Shebzukhov, A.A. Kuchmiy, et al., Accelerated thymic atrophy as a result of elevated homeostatic expression of the genes encoded by the TNF/lymphotoxin cytokine locus, Eur. J. Immunol. 39 (2009) 2906-2915.

[77] L. Boutaffala, M.J.M. Bertrand, C. Remouchamps, G. Seleznik, F. Reisinger, M. Janas, et al., NIK promotes tissue destruction independently of the alternative NF-kB pathway through TNFR1/RIP1-induced apoptosis, Cell Death Differ. 22 (2015) 20202033.

[78] E. Dejardin, N.M. Droin, M. Delhase, E. Haas, Y. Cao, C. Makris, et al., The lymphotoxin-beta receptor induces different patterns of gene expression via two NFkappaB pathways, Immunity. 17 (2002) 525-535.

[79] P. Bista, W. Zeng, S. Ryan, V. Bailly, J.L. Browning, M.E. Lukashev, TRAF3 controls activation of the canonical and alternative NFkappaB by the lymphotoxin beta receptor, J. Biol. Chem. 285 (2010) 12971-12978.

[80] J.R. Müller, U. Siebenlist, Lymphotoxin beta receptor induces sequential activation of distinct NF-kappa B factors via separate signaling pathways, J. Biol. Chem. 278 (2003) 12006-12012.

[81] S. Vallabhapurapu, A. Matsuzawa, W. Zhang, P.-H. Tseng, J.J. Keats, H. Wang, et al., Nonredundant and complementary functions of TRAF2 and TRAF3 in a ubiquitination cascade that activates NIK-dependent alternative NF-kappaB signaling, Nat. Immunol. 9 (2008) 1364-1370.

[82] B.J. Zarnegar, Y. Wang, D.J. Mahoney, P.W. Dempsey, H.H. Cheung, J. He, et al., Noncanonical NF-kappaB activation requires coordinated assembly of a regulatory complex of the adaptors clAP1, clAP2, TRAF2 and TRAF3 and the kinase NIK, Nat. Immunol. 9 (2008) 1371-1378.

[83] H. Sanjo, D.M. Zajonc, R. Braden, P.S. Norris, C.F. Ware, Allosteric regulation of the ubiquitin:NIK and ubiquitin:TRAF3 E3 ligases by the lymphotoxin-beta receptor, J. Biol. Chem. 285 (2010) 17148-17155.

[84] B. Razani, B. Zarnegar, A.J. Ytterberg, T. Shiba, P.W. Dempsey, C.F. Ware, et al., Negative feedback in noncanonical NF-kappaB signaling modulates NIK stability through IKKalpha-mediated phosphorylation, Sci. Signal. 3 (2010) ra41.

[85] G. Liao, M. Zhang, E.W. Harhaj, S.-C. Sun, Regulation of the NF-kappaB-inducing kinase by tumor necrosis factor receptor-associated factor 3-induced degradation, J. Biol. Chem. 279 (2004) 26243-26250.

[86] S. Basak, H. Kim, J.D. Kearns, V. Tergaonkar, E. O'Dea, S.L. Werner, et al., A fourth IkappaB protein within the NF-kappaB signaling module, Cell. 128 (2007) 369-381.

[87] L.A. Madge, M.S. Kluger, J.S. Orange, M.J. May, Lymphotoxin-alpha 1 beta 2 and LIGHT induce classical and noncanonical NF-kappa B-dependent proinflammatory gene expression in vascular endothelial cells, J. Immunol. 180 (2008) 3467-3477. 
[88] R. Ettinger, J.L. Browning, S.A. Michie, W. van Ewijk, H.O. McDevitt, Disrupted splenic architecture, but normal lymph node development in mice expressing a soluble lymphotoxin-beta receptor-IgG1 fusion protein, Proc. Natl. Acad. Sci. U. S. A. 93 (1996) 13102-13107.

[89] P.D. Rennert, J.L. Browning, R. Mebius, F. Mackay, P.S. Hochman, Surface lymphotoxin alpha/beta complex is required for the development of peripheral lymphoid organs, J. Exp. Med. 184 (1996) 1999-2006.

[90] S. Scheu, J. Alferink, T. Pötzel, W. Barchet, U. Kalinke, K. Pfeffer, Targeted disruption of LIGHT causes defects in costimulatory $\mathrm{T}$ cell activation and reveals cooperation with lymphotoxin beta in mesenteric lymph node genesis, J. Exp. Med. 195 (2002) 1613-1624.

[91] T.A. Banks, B.T. Rouse, M.K. Kerley, P.J. Blair, V.L. Godfrey, N.A. Kuklin, et al., Lymphotoxin-alpha-deficient mice. Effects on secondary lymphoid organ development and humoral immune responsiveness, J. Immunol. 155 (1995) 1685-1693.

[92] M.B. Alimzhanov, D.V. Kuprash, M.H. Kosco-Vilbois, A. Luz, R.L. Turetskaya, A. Tarakhovsky, et al., Abnormal development of secondary lymphoid tissues in lymphotoxin beta-deficient mice, Proc. Natl. Acad. Sci. U. S. A. 94 (1997) 9302-9307.

[93] K. Kabashima, T.A. Banks, K.M. Ansel, T.T. Lu, C.F. Ware, J.G. Cyster, Intrinsic lymphotoxin-beta receptor requirement for homeostasis of lymphoid tissue dendritic cells, Immunity. 22 (2005) 439-450.

[94] Y.-G. Wang, K.D. Kim, J. Wang, P. Yu, Y.-X. Fu, Stimulating lymphotoxin beta receptor on the dendritic cells is critical for their homeostasis and expansion, J. Immunol. 175 (2005) 6997-7002.

[95] T.A. Banks, S. Rickert, C.A. Benedict, L. Ma, M. Ko, J. Meier, et al., A lymphotoxinIFN-beta axis essential for lymphocyte survival revealed during cytomegalovirus infection, J. Immunol. 174 (2005) 7217-7225.

[96] D. Elewaut, L. Brossay, S.M. Santee, O.V. Naidenko, N. Burdin, H. De Winter, et al., Membrane lymphotoxin is required for the development of different subpopulations of NK T cells, J. Immunol. 165 (2000) 671-679.

[97] B. Silva-Santos, D.J. Pennington, A.C. Hayday, Lymphotoxin-mediated regulation of gammadelta cell differentiation by alphabeta T cell progenitors, Science. 307 (2005) 925-928.

[98] J. Wang, Y.-X. Fu, LIGHT (a cellular ligand for herpes virus entry mediator and lymphotoxin receptor)-mediated thymocyte deletion is dependent on the interaction between TCR and MHC/self-peptide, J. Immunol. 170 (2003) 3986-3993.

[99] Q. Chai, L. Onder, E. Scandella, C. Gil-Cruz, C. Perez-Shibayama, J. Cupovic, et al., Maturation of lymph node fibroblastic reticular cells from myofibroblastic precursors is critical for antiviral immunity, Immunity. 38 (2013) 1013-1024.

[100] L. Zhao, L. Liu, J. Gao, Y. Yang, C. Hu, B. Guo, et al., T lymphocytes maintain structure and function of fibroblastic reticular cells via lymphotoxin (LT)-B, BMC Immunol. 15 (2014) 33.

[101] A. Tumanov, D. Kuprash, M. Lagarkova, S. Grivennikov, K. Abe, A. Shakhov, et al., Distinct role of surface lymphotoxin expressed by $B$ cells in the organization of secondary lymphoid tissues, Immunity. 17 (2002) 239-250.

[102] K.M. Ansel, V.N. Ngo, P.L. Hyman, S.A. Luther, R. Förster, J.D. Sedgwick, et al., A chemokine-driven positive feedback loop organizes lymphoid follicles, Nature. 406 (2000) 309-314.

[103] A. Kratz, A. Campos-Neto, M.S. Hanson, N.H. Ruddle, Chronic inflammation caused by lymphotoxin is lymphoid neogenesis, J. Exp. Med. 183 (1996) 1461-1472.

[104] L. Onder, R. Danuser, E. Scandella, S. Firner, Q. Chai, T. Hehlgans, et al., Endothelial cell-specific lymphotoxin- $\beta$ receptor signaling is critical for lymph node and high endothelial venule formation, J. Exp. Med. 210 (2013) 465-473.

[105] Y. Mouri, M. Yano, M. Shinzawa, Y. Shimo, F. Hirota, Y. Nishikawa, et al., Lymphotoxin signal promotes thymic organogenesis by eliciting RANK expression in the embryonic thymic stroma, J. Immunol. 186 (2011) 5047-5057. 
[106] R.A. Anders, S.K. Subudhi, J. Wang, K. Pfeffer, Y.-X. Fu, Contribution of the lymphotoxin beta receptor to liver regeneration, J. Immunol. 175 (2005) 1295-1300.

[107] C. Bénézech, E. Mader, G. Desanti, M. Khan, K. Nakamura, A. White, et al., Lymphotoxin- $\beta$ receptor signaling through NF-KB2-RelB pathway reprograms adipocyte precursors as lymph node stromal cells, Immunity. 37 (2012) 721-734.

[108] N.H. Ruddle, Lymphotoxin and TNF: how it all began-a tribute to the travelers, Cytokine Growth Factor Rev. 25 (2014) 83-89.

[109] D. Yang, N. Ud Din, D.D. Browning, S.I. Abrams, K. Liu, Targeting lymphotoxin beta receptor with tumor-specific T lymphocytes for tumor regression, Clin. Cancer Res. 13 (2007) 5202-5210.

[110] Y. Kashii, R. Giorda, R.B. Herberman, T.L. Whiteside, N.L. Vujanovic, Constitutive expression and role of the TNF family ligands in apoptotic killing of tumor cells by human NK cells, J. Immunol. 163 (1999) 5358-5366.

[111] G. Lu, B.M. Janjic, J. Janjic, T.L. Whiteside, W.J. Storkus, N.L. Vujanovic, Innate direct anticancer effector function of human immature dendritic cells. II. Role of TNF, lymphotoxin-alpha(1)beta(2), Fas ligand, and TNF-related apoptosis-inducing ligand, J. Immunol. 168 (2002) 1831-1839.

[112] H. Winter, N.K. van den Engel, C.H. Poehlein, R.A. Hatz, B.A. Fox, H.-M. Hu, Tumorspecific $T$ cells signal tumor destruction via the lymphotoxin beta receptor, J. Transl. Med. 5 (2007) 14.

[113] P. Yu, Y. Lee, W. Liu, R.K. Chin, J. Wang, Y. Wang, et al., Priming of naive T cells inside tumors leads to eradication of established tumors, Nat. Immunol. 5 (2004) 141149.

[114] M. Loeffler, G. Le'Negrate, M. Krajewska, J.C. Reed, Attenuated Salmonella engineered to produce human cytokine LIGHT inhibit tumor growth, Proc. Natl. Acad. Sci. U. S. A. 104 (2007) 12879-12883.

[115] R. Mortarini, A. Scarito, D. Nonaka, M. Zanon, I. Bersani, E. Montaldi, et al., Constitutive expression and costimulatory function of LIGHT/TNFSF14 on human melanoma cells and melanoma-derived microvesicles, Cancer Res. 65 (2005) 34283436.

[116] P. Yu, Y. Lee, Y. Wang, X. Liu, S. Auh, T.F. Gajewski, et al., Targeting the primary tumor to generate CTL for the effective eradication of spontaneous metastases, $\mathrm{J}$. Immunol. 179 (2007) 1960-1968.

[117] J.P. Hindley, E. Jones, K. Smart, H. Bridgeman, S.N. Lauder, B. Ondondo, et al., Tcell trafficking facilitated by high endothelial venules is required for tumor control after regulatory T-cell depletion, Cancer Res. 72 (2012) 5473-5482.

[118] L. Martinet, T. Filleron, S. Le Guellec, P. Rochaix, I. Garrido, J.-P. Girard, High Endothelial Venule Blood Vessels for Tumor-Infiltrating Lymphocytes Are Associated with Lymphotoxin $\beta$-Producing Dendritic Cells in Human Breast Cancer, J. Immunol. (2013).

[119] D.L. Drayton, S. Liao, R.H. Mounzer, N.H. Ruddle, Lymphoid organ development: from ontogeny to neogenesis, Nat. Immunol. 7 (2006) 344-353.

[120] L. Martinet, S. Le Guellec, T. Filleron, L. Lamant, N. Meyer, P. Rochaix, et al., High endothelial venules (HEVs) in human melanoma lesions: Major gateways for tumorinfiltrating lymphocytes, Oncoimmunology. 1 (2012) 829-839.

[121] J.-P. Girard, C. Moussion, R. Förster, HEVs, lymphatics and homeostatic immune cell trafficking in lymph nodes, Nat. Rev. Immunol. 12 (2012) 762-773.

[122] Y.Y.-Y. Or, G.T.-Y. Chung, K.-F. To, C. Chow, K.-W. Choy, C.Y.-K. Tong, et al., Identification of a novel 12p13.3 amplicon in nasopharyngeal carcinoma, J. Pathol. 220 (2010) 97-107.

[123] S. Fujiwara, Y. Yamashita, Y.L. Choi, T. Wada, R. Kaneda, S. Takada, et al., Transforming activity of the lymphotoxin-beta receptor revealed by expression screening, Biochem. Biophys. Res. Commun. 338 (2005) 1256-1262. 
[124] J.J. Keats, R. Fonseca, M. Chesi, R. Schop, A. Baker, W.-J. Chng, et al., Promiscuous mutations activate the noncanonical NF-kappaB pathway in multiple myeloma, Cancer Cell. 12 (2007) 131-144.

[125] G.T.-Y. Chung, W.P.-K. Lou, C. Chow, K.-F. To, K.-W. Choy, A.W.-C. Leung, et al., Constitutive activation of distinct NF-KB signals in EBV-associated nasopharyngeal carcinoma, J. Pathol. 231 (2013) 311-322.

[126] L. Yang, R. Feng, G. Liu, M. Liao, L. Zhang, W. Wang, TNF- $\beta+252$ A>G polymorphism and susceptibility to cancer, J. Cancer Res. Clin. Oncol. 139 (2013) 765-772.

[127] X. Yu, Y. Huang, C. Li, H. Yang, C. Lu, S. Duan, Positive association between lymphotoxin-alpha variation rs909253 and cancer risk: a meta-analysis based on 36 case-control studies, Tumour Biol. 35 (2014) 1973-1983.

[128] J. Liu, J. Liu, B. Song, T. Wang, Y. Liu, J. Hao, et al., Genetic variations in CTLA-4, TNF- $\alpha$, and LTA and susceptibility to T-cell lymphoma in a Chinese population, Cancer Epidemiol. 37 (2013) 930-934.

[129] C.F. Skibola, P.M. Bracci, A. Nieters, A. Brooks-Wilson, S. de Sanjosé, A.M. Hughes, et al., Tumor necrosis factor (TNF) and lymphotoxin-alpha (LTA) polymorphisms and risk of non-Hodgkin lymphoma in the InterLymph Consortium, Am. J. Epidemiol. 171 (2010) 267-276.

[130] I. Kohaar, P. Tiwari, R. Kumar, V. Nasare, N. Thakur, B.C. Das, et al., Association of single nucleotide polymorphisms (SNPs) in TNF-LTA locus with breast cancer risk in Indian population, Breast Cancer Res. Treat. 114 (2009) 347-355.

[131] P. Zhou, W. Huang, X. Chu, L.-F. Du, J.-P. Li, C. Zhang, The lymphotoxin-a 252A>G polymorphism and breast cancer: a meta-analysis, Asian Pac. J. Cancer Prev. 13 (2012) 1949-1952.

[132] R. Lu, X. Dou, X. Gao, J. Zhang, J. Ni, L. Guo, A functional polymorphism of lymphotoxin-alpha (LTA) gene rs909253 is associated with gastric cancer risk in an Asian population, Cancer Epidemiol. 36 (2012) e380-386.

[133] Z. Xu, R. Shi, R. Zhang, D. Zhang, L. Wang, Association between tumor necrosis factor $\beta 252$ A/G polymorphism and risk of gastric cancer: a meta-analysis, Tumour Biol. 34 (2013) 4001-4005.

[134] G. Messer, U. Spengler, M.C. Jung, G. Honold, K. Blömer, G.R. Pape, et al., Polymorphic structure of the tumor necrosis factor (TNF) locus: an Ncol polymorphism in the first intron of the human TNF-beta gene correlates with a variant amino acid in position 26 and a reduced level of TNF-beta production, J. Exp. Med. 173 (1991) 209219.

[135] K. Ozaki, Y. Ohnishi, A. lida, A. Sekine, R. Yamada, T. Tsunoda, et al., Functional SNPs in the lymphotoxin-alpha gene that are associated with susceptibility to myocardial infarction, Nat. Genet. 32 (2002) 650-654.

[136] C.F. Ware, Network communications: lymphotoxins, LIGHT, and TNF, Annu. Rev. Immunol. 23 (2005) 787-819.

[137] R. Chovatiya, R. Medzhitov, Stress, inflammation, and defense of homeostasis, Mol. Cell. 54 (2014) 281-288.

[138] L.M. Coussens, Z. Werb, Inflammation and cancer, Nature. 420 (2002) 860-867.

[139] D. Hanahan, J. Folkman, Patterns and emerging mechanisms of the angiogenic switch during tumorigenesis, Cell. 86 (1996) 353-364.

[140] B. Daller, W. Müsch, J. Röhrl, A.V. Tumanov, S.A. Nedospasov, D.N. Männel, et al., Lymphotoxin- $\beta$ receptor activation by lymphotoxin- $\alpha(1) \beta(2)$ and LIGHT promotes tumor growth in an NFKB-dependent manner, Int. J. Cancer. 128 (2011) 1363-1370.

[141] T. Hehlgans, B. Stoelcker, P. Stopfer, P. Müller, G. Cernaianu, M. Guba, et al., Lymphotoxin-beta receptor immune interaction promotes tumor growth by inducing angiogenesis, Cancer Res. 62 (2002) 4034-4040.

[142] A. Mantovani, P. Allavena, A. Sica, F. Balkwill, Cancer-related inflammation, Nature. 454 (2008) 436-444. 
[143] J. Lucifora, Y. Xia, F. Reisinger, K. Zhang, D. Stadler, X. Cheng, et al., Specific and nonhepatotoxic degradation of nuclear hepatitis B virus cccDNA, Science. 343 (2014) 1221-1228.

[144] M.J. Wolf, A. Adili, K. Piotrowitz, Z. Abdullah, Y. Boege, K. Stemmer, et al., Metabolic activation of intrahepatic CD8+ $T$ cells and NKT cells causes nonalcoholic steatohepatitis and liver cancer via cross-talk with hepatocytes, Cancer Cell. 26 (2014) 549-564.

[145] A.J. Scarzello, Q. Jiang, T. Back, H. Dang, D. Hodge, C. Hanson, et al., LTßR signalling preferentially accelerates oncogenic AKT-initiated liver tumours, Gut. (2015). doi:10.1136/gutjnl-2014-308810.

[146] M. Ammirante, J.-L. Luo, S. Grivennikov, S. Nedospasov, M. Karin, B-cell-derived lymphotoxin promotes castration-resistant prostate cancer, Nature. 464 (2010) 302305.

[147] Y. He, J. Zha, Y. Wang, W. Liu, X. Yang, P. Yu, Tissue damage-associated "danger signals" influence T-cell responses that promote the progression of preneoplasia to cancer, Cancer Res. 73 (2013) 629-639.

[148] T.-S. Lau, T.K.-H. Chung, T.-H. Cheung, L.K.-Y. Chan, L.W.-H. Cheung, S.-F. Yim, et al., Cancer cell-derived lymphotoxin mediates reciprocal tumour-stromal interactions in human ovarian cancer by inducing CXCL11 in fibroblasts, J. Pathol. 232 (2014) 4356.

[149] I.S. Khan, M.L. Mouchess, M.-L. Zhu, B. Conley, K.J. Fasano, Y. Hou, et al., Enhancement of an anti-tumor immune response by transient blockade of central $T$ cell tolerance, J. Exp. Med. 211 (2014) 761-768.

[150] P. Zhou, X. Fang, B.A. McNally, P. Yu, M. Zhu, Y.-X. Fu, et al., Targeting lymphotoxin-mediated negative selection to prevent prostate cancer in mice with genetic predisposition, Proc. Natl. Acad. Sci. U. S. A. 106 (2009) 17134-17139.

[151] C.M. Annunziata, R.E. Davis, Y. Demchenko, W. Bellamy, A. Gabrea, F. Zhan, et al., Frequent engagement of the classical and alternative NF-kappaB pathways by diverse genetic abnormalities in multiple myeloma, Cancer Cell. 12 (2007) 115-130.

[152] A. Rehm, A. Mensen, K. Schradi, K. Gerlach, S. Wittstock, S. Winter, et al., Cooperative function of CCR7 and lymphotoxin in the formation of a lymphomapermissive niche within murine secondary lymphoid organs, Blood. 118 (2011) 10201033.

[153] K. Heinig, M. Gätjen, M. Grau, V. Stache, I. Anagnostopoulos, K. Gerlach, et al., Access to follicular dendritic cells is a pivotal step in murine chronic lymphocytic leukemia B-cell activation and proliferation, Cancer Discov. 4 (2014) 1448-1465.

[154] M.T. Fernandes, M.N. Ghezzo, A.B. Silveira, R.K. Kalathur, V. Póvoa, A.R. Ribeiro, et al., Lymphotoxin- $\beta$ receptor in microenvironmental cells promotes the development of T-cell acute lymphoblastic leukaemia with cortical/mature immunophenotype, Br. J. Haematol. 171 (2015) 736-751.

[155] N.R. dos Santos, M. Williame, S. Gachet, F. Cormier, A. Janin, D. Weih, et al., RelBdependent stromal cells promote T-cell leukemogenesis, PloS One. 3 (2008) e2555.

[156] C. Tournier, The 2 Faces of JNK Signaling in Cancer, Genes Cancer. 4 (2013) 397400.

[157] F. Partheniou, S.M. Kelsey, S.M. Srinivasula, A.C. Newland, E.S. Alnemri, L. Jia, cIAP1 blocks TNFalpha-mediated cytotoxicity upstream of caspase-dependent and independent mitochondrial events in human leukemic cells, Biochem. Biophys. Res. Commun. 287 (2001) 181-189.

[158] N. Watanabe, Y. Niitsu, H. Umeno, H. Kuriyama, H. Neda, N. Yamauchi, et al., Toxic effect of tumor necrosis factor on tumor vasculature in mice, Cancer Res. 48 (1988) 2179-2183.

[159] V.A. Polunovsky, C.H. Wendt, D.H. Ingbar, M.S. Peterson, P.B. Bitterman, Induction of endothelial cell apoptosis by TNF alpha: modulation by inhibitors of protein synthesis, Exp. Cell Res. 214 (1994) 584-594. 
[160] M.A. Palladino, M.R. Shalaby, S.M. Kramer, B.L. Ferraiolo, R.A. Baughman, A.B. Deleo, et al., Characterization of the antitumor activities of human tumor necrosis factor-alpha and the comparison with other cytokines: induction of tumor-specific immunity, J. Immunol. 138 (1987) 4023-4032.

[161] T. Blankenstein, Z.H. Qin, K. Uberla, W. Müller, H. Rosen, H.D. Volk, et al., Tumor suppression after tumor cell-targeted tumor necrosis factor alpha gene transfer, J. Exp. Med. 173 (1991) 1047-1052.

[162] C.N. Baxevanis, I.F. Voutsas, O.E. Tsitsilonis, M.L. Tsiatas, A.D. Gritzapis, M. Papamichail, Compromised anti-tumor responses in tumor necrosis factor-alpha knockout mice, Eur. J. Immunol. 30 (2000) 1957-1966.

[163] J. Nakashima, M. Tachibana, M. Ueno, A. Miyajima, S. Baba, M. Murai, Association between tumor necrosis factor in serum and cachexia in patients with prostate cancer, Clin. Cancer Res. Off. J. Am. Assoc. Cancer Res. 4 (1998) 1743-1748.

[164] A. Ferrajoli, M.J. Keating, T. Manshouri, F.J. Giles, A. Dey, Z. Estrov, et al., The clinical significance of tumor necrosis factor-alpha plasma level in patients having chronic lymphocytic leukemia, Blood. 100 (2002) 1215-1219.

[165] V. Michalaki, K. Syrigos, P. Charles, J. Waxman, Serum levels of IL-6 and TNF-alpha correlate with clinicopathological features and patient survival in patients with prostate cancer, Br. J. Cancer. 90 (2004) 2312-2316.

[166] P. Orosz, B. Echtenacher, W. Falk, J. Rüschoff, D. Weber, D.N. Männel, Enhancement of experimental metastasis by tumor necrosis factor, J. Exp. Med. 177 (1993) 1391-1398.

[167] R.J. Moore, D.M. Owens, G. Stamp, C. Arnott, F. Burke, N. East, et al., Mice deficient in tumor necrosis factor-alpha are resistant to skin carcinogenesis, Nat. Med. 5 (1999) 828-831.

[168] M. Suganuma, S. Okabe, M.W. Marino, A. Sakai, E. Sueoka, H. Fujiki, Essential role of tumor necrosis factor alpha (TNF-alpha) in tumor promotion as revealed by TNFalpha-deficient mice, Cancer Res. 59 (1999) 4516-4518.

[169] B. Yan, H. Wang, Z.N. Rabbani, Y. Zhao, W. Li, Y. Yuan, et al., Tumor necrosis factor-alpha is a potent endogenous mutagen that promotes cellular transformation, Cancer Res. 66 (2006) 11565-11570.

[170] B.K. Popivanova, K. Kitamura, Y. Wu, T. Kondo, T. Kagaya, S. Kaneko, et al., Blocking TNF-alpha in mice reduces colorectal carcinogenesis associated with chronic colitis, J. Clin. Invest. 118 (2008) 560-570.

[171] S. Mocellin, C.R. Rossi, P. Pilati, D. Nitti, Tumor necrosis factor, cancer and anticancer therapy, Cytokine Growth Factor Rev. 16 (2005) 35-53.

[172] B. Bierie, H.L. Moses, Transforming growth factor beta (TGF-beta) and inflammation in cancer, Cytokine Growth Factor Rev. 21 (2010) 49-59.

[173] E. Meulmeester, P. Ten Dijke, The dynamic roles of TGF- $\beta$ in cancer, J. Pathol. 223 (2011) 205-218.

[174] D.R. Principe, J.A. Doll, J. Bauer, B. Jung, H.G. Munshi, L. Bartholin, et al., TGF- $\beta$ : duality of function between tumor prevention and carcinogenesis, J. Natl. Cancer Inst. 106 (2014) djt369.

[175] B. Bierie, H.L. Moses, Tumour microenvironment: TGFbeta: the molecular Jekyll and Hyde of cancer, Nat. Rev. Cancer. 6 (2006) 506-520.

[176] N.A. Bhowmick, A. Chytil, D. Plieth, A.E. Gorska, N. Dumont, S. Shappell, et al., TGFbeta signaling in fibroblasts modulates the oncogenic potential of adjacent epithelia, Science. 303 (2004) 848-851.

[177] L. Yang, J. Huang, X. Ren, A.E. Gorska, A. Chytil, M. Aakre, et al., Abrogation of TGF beta signaling in mammary carcinomas recruits $\mathrm{Gr}-1+\mathrm{CD} 11 \mathrm{~b}+$ myeloid cells that promote metastasis, Cancer Cell. 13 (2008) 23-35.

[178] L. Gorelik, R.A. Flavell, Immune-mediated eradication of tumors through the blockade of transforming growth factor-beta signaling in T cells, Nat. Med. 7 (2001) 1118-1122. 
[179] Y.-A. Yang, O. Dukhanina, B. Tang, M. Mamura, J.J. Letterio, J. MacGregor, et al., Lifetime exposure to a soluble TGF-beta antagonist protects mice against metastasis without adverse side effects, J. Clin. Invest. 109 (2002) 1607-1615.

[180] D.A. Thomas, J. Massagué, TGF-beta directly targets cytotoxic T cell functions during tumor evasion of immune surveillance, Cancer Cell. 8 (2005) 369-380.

[181] A.P. Weng, A.A. Ferrando, W. Lee, J.P. Morris, L.B. Silverman, C. Sanchez-Irizarry, et al., Activating mutations of $\mathrm{NOTCH} 1$ in human $\mathrm{T}$ cell acute lymphoblastic leukemia, Science. 306 (2004) 269-271.

[182] M. Di lanni, S. Baldoni, E. Rosati, R. Ciurnelli, L. Cavalli, M.F. Martelli, et al., A new genetic lesion in B-CLL: a NOTCH1 PEST domain mutation, Br. J. Haematol. 146 (2009) 689-691.

[183] R. Kridel, B. Meissner, S. Rogic, M. Boyle, A. Telenius, B. Woolcock, et al., Whole transcriptome sequencing reveals recurrent $\mathrm{NOTCH} 1$ mutations in mantle cell lymphoma, Blood. 119 (2012) 1963-1971.

[184] D.R. Robinson, S. Kalyana-Sundaram, Y.-M. Wu, S. Shankar, X. Cao, B. Ateeq, et al., Functionally recurrent rearrangements of the MAST kinase and Notch gene families in breast cancer, Nat. Med. 17 (2011) 1646-1651.

[185] D. Rossi, V. Trifonov, M. Fangazio, A. Bruscaggin, S. Rasi, V. Spina, et al., The coding genome of splenic marginal zone lymphoma: activation of NOTCH2 and other pathways regulating marginal zone development, J. Exp. Med. 209 (2012) 15371551.

[186] M.J. Kiel, T. Velusamy, B.L. Betz, L. Zhao, H.G. Weigelin, M.Y. Chiang, et al., Wholegenome sequencing identifies recurrent somatic NOTCH2 mutations in splenic marginal zone lymphoma, J. Exp. Med. 209 (2012) 1553-1565.

[187] A.P. South, R.J. Cho, J.C. Aster, The double-edged sword of Notch signaling in cancer, Semin. Cell Dev. Biol. 23 (2012) 458-464.

[188] N. Stransky, A.M. Egloff, A.D. Tward, A.D. Kostic, K. Cibulskis, A. Sivachenko, et al., The mutational landscape of head and neck squamous cell carcinoma, Science. 333 (2011) 1157-1160.

[189] N. Agrawal, M.J. Frederick, C.R. Pickering, C. Bettegowda, K. Chang, R.J. Li, et al., Exome sequencing of head and neck squamous cell carcinoma reveals inactivating mutations in NOTCH1, Science. 333 (2011) 1154-1157.

[190] N.J. Wang, Z. Sanborn, K.L. Arnett, L.J. Bayston, W. Liao, C.M. Proby, et al., Loss-offunction mutations in Notch receptors in cutaneous and lung squamous cell carcinoma, Proc. Natl. Acad. Sci. U. S. A. 108 (2011) 17761-17766.

[191] A. Klinakis, C. Lobry, O. Abdel-Wahab, P. Oh, H. Haeno, S. Buonamici, et al., A novel tumour-suppressor function for the Notch pathway in myeloid leukaemia, Nature. 473 (2011) 230-233.

[192] S. Kannan, R.M. Sutphin, M.G. Hall, L.S. Golfman, W. Fang, R.M. Nolo, et al., Notch activation inhibits AML growth and survival: a potential therapeutic approach, J. Exp. Med. 210 (2013) 321-337.

[193] C. Lobry, P. Ntziachristos, D. Ndiaye-Lobry, P. Oh, L. Cimmino, N. Zhu, et al., Notch pathway activation targets AML-initiating cell homeostasis and differentiation, J. Exp. Med. 210 (2013) 301-319.

[194] C. Lobry, P. Oh, M.R. Mansour, A.T. Look, I. Aifantis, Notch signaling: switching an oncogene to a tumor suppressor, Blood. 123 (2014) 2451-2459.

[195] N.D. Perkins, The diverse and complex roles of NF-kB subunits in cancer, Nat. Rev. Cancer. 12 (2012) 121-132.

[196] K.M. Ryan, M.K. Ernst, N.R. Rice, K.H. Vousden, Role of NF-kappaB in p53-mediated programmed cell death, Nature. 404 (2000) 892-897.

[197] S. Rocha, K.J. Campbell, N.D. Perkins, p53- and Mdm2-independent repression of NF-kappa B transactivation by the ARF tumor suppressor, Mol. Cell. 12 (2003) 15-25.

[198] Y. Chien, C. Scuoppo, X. Wang, X. Fang, B. Balgley, J.E. Bolden, et al., Control of the senescence-associated secretory phenotype by NF-kB promotes senescence and enhances chemosensitivity, Genes Dev. 25 (2011) 2125-2136. 
[199] H. Jing, J. Kase, J.R. Dörr, M. Milanovic, D. Lenze, M. Grau, et al., Opposing roles of NF-KB in anti-cancer treatment outcome unveiled by cross-species investigations, Genes Dev. 25 (2011) 2137-2146.

[200] R.L. Bjordahl, C. Steidl, R.D. Gascoyne, C.F. Ware, Lymphotoxin network pathways shape the tumor microenvironment, Curr. Opin. Immunol. 25 (2013) 222-229. 


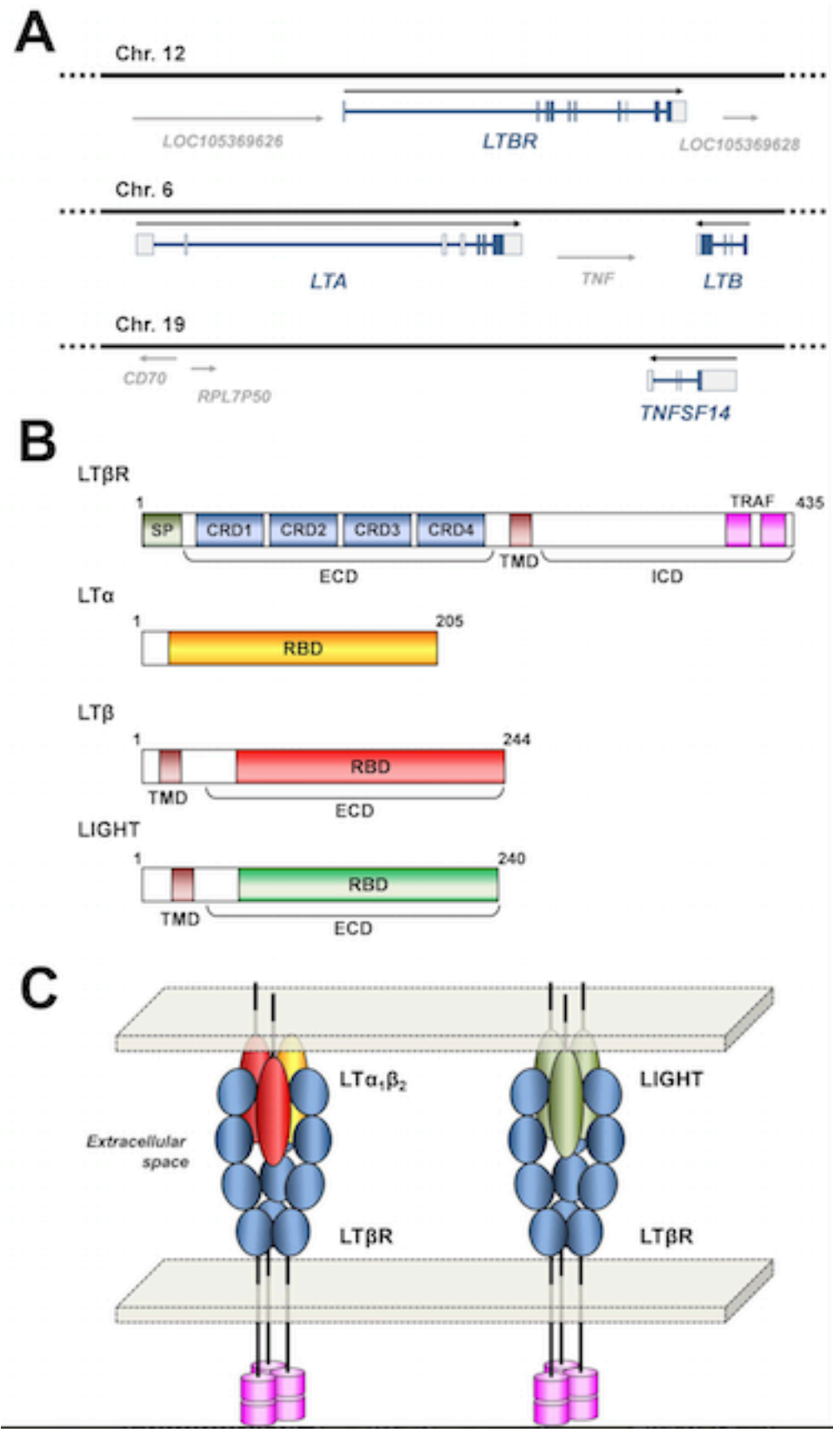

Figure 1. LT $\beta R$, lymphotoxin and LIGHT proteins and genes. A) Genomic localization and exon-intron structure of LTBR, LTA, LTB, and TNFSF14/LIGHT human genes. Boxes represent exons, blue being coding and grey non-coding regions. B) Schematic representation of the LT $\beta R$, LTa, LT $\beta$, and LIGHT protein primary structure. Numbers represent amino acid position. CRD, cysteine-rich domain; ECD, extracellular domain; ICD, intracellular domain; RBD, receptor-binding domain; SP, signal peptide; TMD, transmembrane domain; TRAF, TRAF protein-binding domains. C) Schematic representation of interaction between $L T \beta R$ and its two main ligands, $L T \alpha_{1} \beta_{2}$ heterotrimers (left) and LIGHT homotrimers (right). Blue shapes represent LT $\beta R$ CRDs interacting with the groove formed each by 2 ligand subunits. Pink shapes represent TRAF binding domains. 


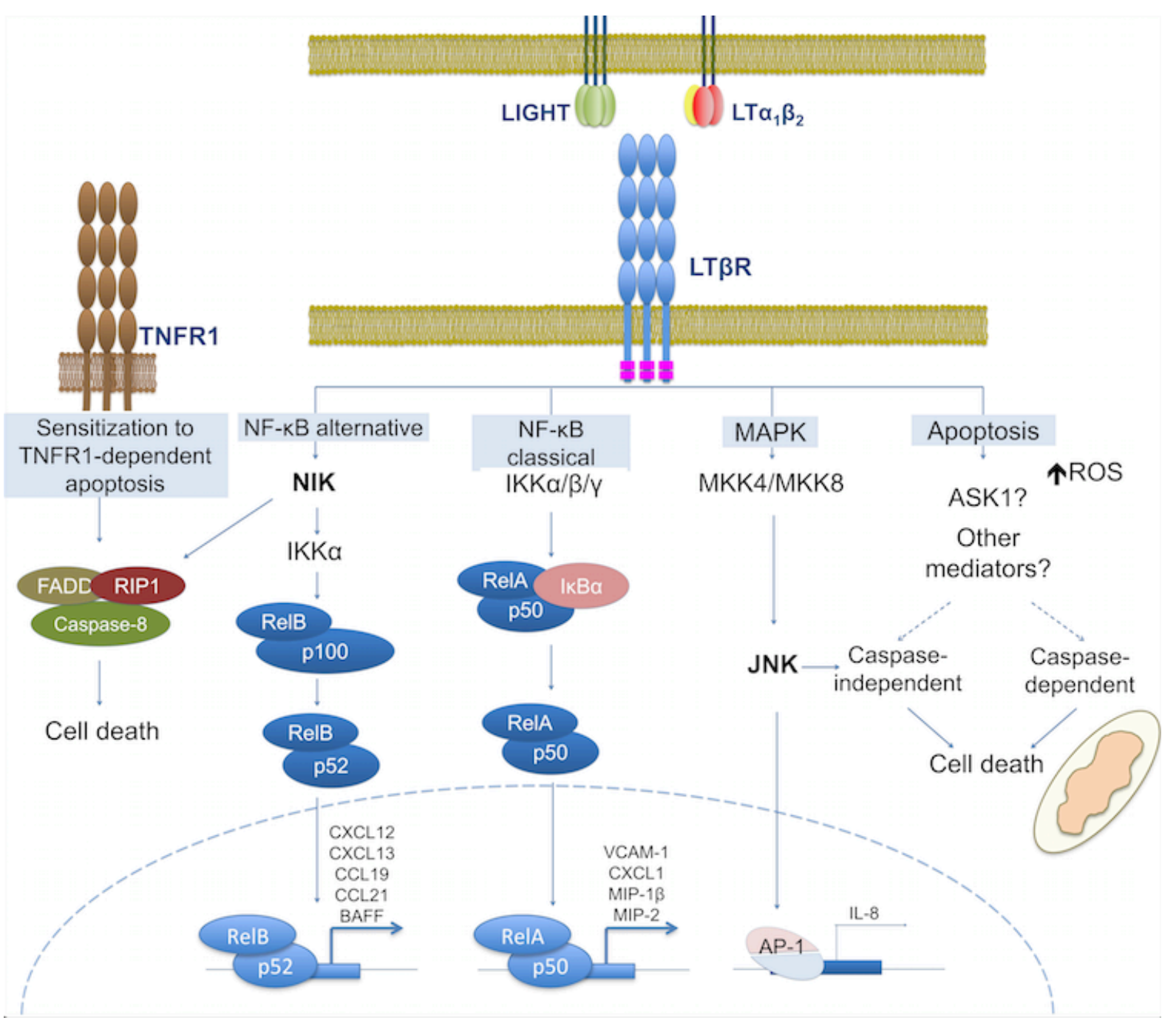

Figure 2. LT $\beta$ R-mediated signal transduction pathways leading to target gene expression and cell death. Activation of LT $\beta R$ signaling by LIGHT or $L T \alpha_{1} \beta_{2}$ can induce specific target gene expression and cell death. NF-kB classical pathway induction leads sequentially to activation of the IKK complex, IKK-mediated IKBa phosphorylation and subsequent degradation, nuclear translocation of RelA/p50 heterodimers, and induction of pro-inflammatory cytokine, chemokine, and adhesion molecule expression. On the other hand, the alternative NF-KB pathway relies on NIK and IKKa-dependent processing of p100 into p52, leading to the translocation of RelB/p52 heterodimers to the nucleus where they activate the expression of genes mainly involved in lymphoid organogenesis and homeostasis. LTßR-induced activation of NIK is also involved in TNFR1-mediated RIP1dependent apoptosis. Furthermore, LT $\beta$ R activation induces cell death by other illcharacterized mechanisms involving reactive oxygen species (ROS) production, ASK-1, and either caspase-independent or caspase-dependent apoptosis. LT $\beta R$ was also shown to activate JNK leading to AP-1-induced gene expression in addition to cell death. 

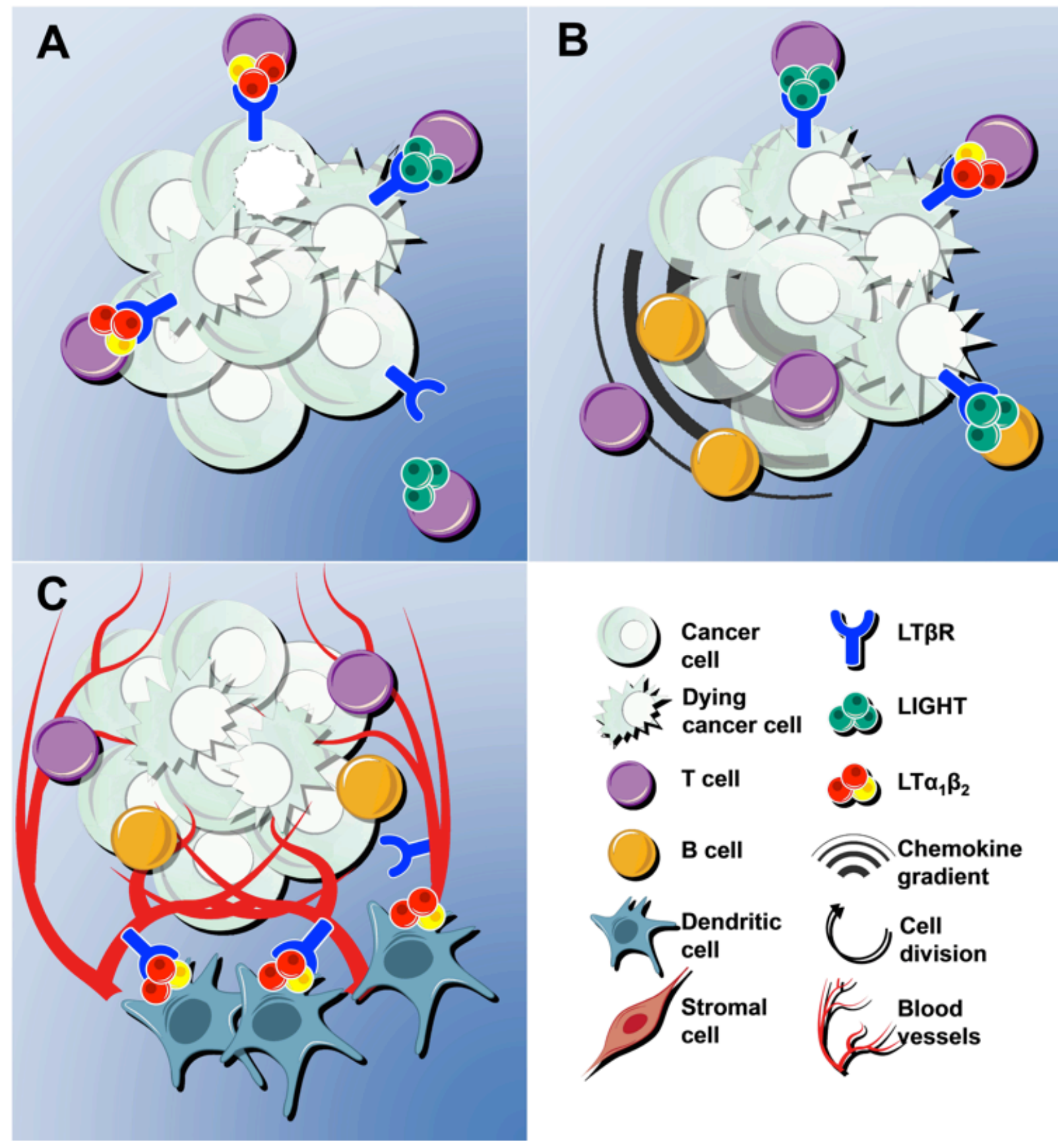

Figure 3. LT $\beta R$ anti-oncogenic roles. Activation of $L T \beta R$ signaling leads to anti-oncogenic effects due to three main mechanisms. A) Death of LT $\beta R$-expressing cancer cells likely induced by immune cells expressing $L \mathrm{La}_{1} \beta_{2}$ and/or LIGHT. B) Recruitment of anti-cancer $\mathrm{LTa}_{1} \beta_{2^{-}}$and/or LIGHT-expressing immune cells mediated by LT $\beta R$-expressing cancer or stromal cell chemokine production [112,113]. C) Increased anti-tumor immune response linked to high endothelial venule neogenesis triggered by LT $\beta R$ stimulation of endothelial cells by $L T \alpha_{1} \beta_{2}$-expressing DCs [118]. 

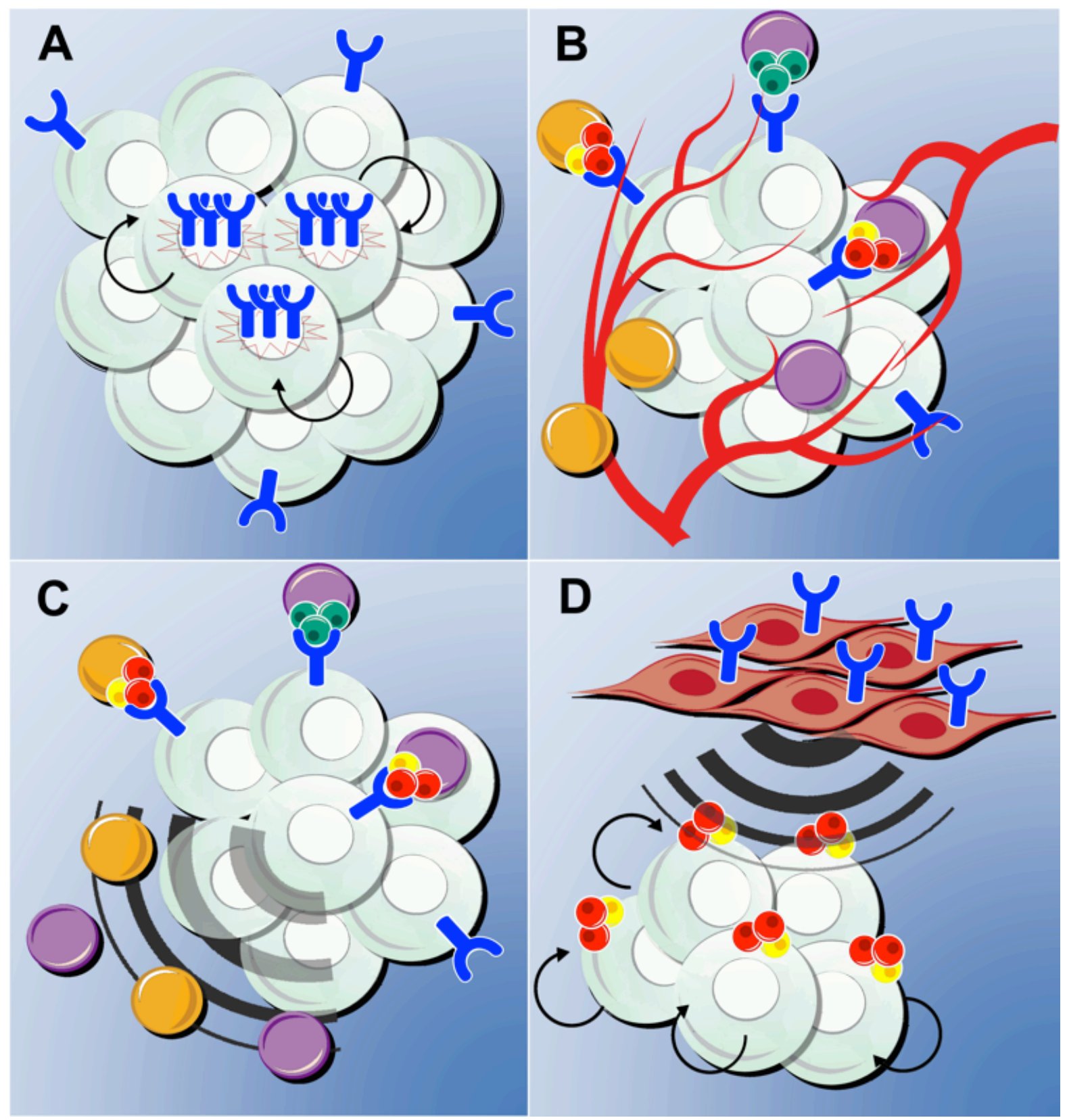

Figure 4. LT $\beta R$ pro-oncogenic roles. Activation of $L T \beta R$ signaling favors oncogenesis due to four main mechanisms. A) Genetic alterations in the LTBR gene leading either to its overexpression or the expression of alternative forms, result in ligand-independent LT $\beta R$ activation, which supports cancer cell proliferation and/or survival [65,122-124]. B) LTa $\beta_{1} \beta_{2^{-}}$ and LIGHT-expressing lymphocytes induce pro-angiogenic factors in LT $\beta R$-expressing cancer cells and induce angiogenesis [140,141]. C) LTa $\beta_{1} \beta_{2^{-}}$and LIGHT-expressing lymphocytes induce chemokines in LT $\beta R$-expressing cancer cells, thus fostering a prooncogenic inflammatory microenvironment $[13,43,146,147]$. D) $L T \alpha_{1} \beta_{2}$-expressing cancer cells induce production of chemokines and pro-survival factors in LT $\beta$ R-expressing tumor stromal cells, thus triggering cancer cell migration and favoring tumor progression [148,152154]. See Figure 3 for symbol legend. 